\title{
Intrinsic Mechanisms of Frequency Selectivity in the Proximal Dendrites of CA1 Pyramidal Neurons
}

\author{
[Crescent L. Combe, ${ }^{1}$ Carmen C. Canavier, ${ }^{2}$ and 1 Sonia Gasparini ${ }^{1,2}$ \\ ${ }^{1}$ Neuroscience Center, Louisiana State University Health Sciences Center, New Orleans, Louisiana 70112 and ${ }^{2}$ Department of Cell Biology and Anatomy, \\ Louisiana State University Health Sciences Center, New Orleans, Louisiana 70112
}

Gamma oscillations are thought to play a role in learning and memory. Two distinct bands, slow $(25-50 \mathrm{~Hz})$ and fast $(65-100 \mathrm{~Hz})$ gamma, have been identified in area CA1 of the rodent hippocampus. Slow gamma is phase locked to activity in area CA3 and presumably driven by the Schaffer collaterals (SCs). We used a combination of computational modeling and in vitro electrophysiology in hippocampal slices of male rats to test whether CA1 neurons responded to SC stimulation selectively at slow gamma frequencies and to identify the mechanisms involved. Both approaches demonstrated that, in response to temporally precise input at SCs, CA1 pyramidal neurons fire preferentially in the slow gamma range regardless of whether the input is at fast or slow gamma frequencies, suggesting frequency selectivity in CA1 output with respect to CA3 input. In addition, phase locking, assessed by the vector strength, was more precise for slow gamma than fast gamma input. This frequency selectivity was greatly attenuated when the slow $\mathrm{Ca}^{2+}$-dependent $\mathrm{K}^{+}$(SK) current was removed from the model or blocked in vitro with apamin. Perfusion of slices with $\mathrm{BaCl}_{2}$ to block A-type $\mathrm{K}^{+}$channels tightened this frequency selectivity. Both the broad-spectrum cholinergic agonist carbachol and the muscarinic agonist oxotremorine-M greatly attenuated the selectivity. The more precise firing at slower frequencies persisted throughout all of the pharmacological manipulations conducted. We propose that these intrinsic mechanisms provide a means by which CA1 phase locks to CA3 at different gamma frequencies preferentially in vivo as physiological conditions change with behavioral demands.

Key words: dendrite; synaptic transmission; synchronization

\section{Significance Statement}

Gamma frequency activity, one of multiple bands of synchronous activity, has been suggested to underlie various aspects of hippocampal function. Multisite recordings within the rat hippocampal formation indicate that different behavioral tasks are associated with synchronized activity between areas CA3 and CA1 at two different gamma bands: slow and fast gamma. In this study, we examine the intrinsic mechanisms that may allow CA1 to selectively "listen" to CA3 at slow compared with fast gamma and suggest mechanisms that gate this selectivity. Identifying the intrinsic mechanisms underlying differential gamma preference may help to explain the distinct types of CA3-CA1 synchronization observed in vivo under different behavioral conditions.

\section{Introduction}

Coordinated activity within the hippocampal formation is thought to facilitate information flow and underlie information

\footnotetext{
Received Feb. 16, 2018; revised July 23, 2018; accepted July 24, 2018

Author contributions: C.C.C. and S.G. designed research; C.L.C., C.C.C., and S.G. performed research; C.L.C., C.C.C., and S.G. analyzed data; C.L.C., C.C.C., and S.G. wrote the paper.

This work was supported by the National Institutes of Health (Grant R01 MH115832 under the Collaborative Research in Computational Neuroscience program to co-principal investigators C.C.C. and S.G.) and the Research Enhancement Program of the School of Medicine at the Louisiana State University Health Sciences Center (S.G.). We thank Benjamin Bonner for simulations and parameter adjustments that led to the current version of the model, Ruben Tikidji-Hamburyan for implementing the pc $2 b$ morphology and other assistance with the code, Christopher Knowlton for writing analysis routines, and Antonio Fernández-Ruiz for helpful discussion.

The authors declare no competing financial interests.

Correspondence should be addressed to Crescent L. Combe, Neuroscience Center, LSUHSC, Suite D, Room 905 Lions, 2020 Gravier St., New Orleans, LA 70112. E-mail: ccomb1@|suhsc.edu.

DOI:10.1523/JNEUROSCI.0449-18.2018

Copyright $@ 2018$ the authors $\quad 0270-6474 / 18 / 388110-18 \$ 15.00 / 0$
}

storage and is observable at multiple levels, from synchronized firing of individual neurons to population level oscillations at different frequencies (Düzel et al., 2010; Jutras and Buffalo, 2010). Within the hippocampal formation, there are multiple sources of gamma frequency activity that transiently link subregions (Colgin et al., 2009; Schomburg et al., 2014). Alternating synchrony between subregions may be instrumental in routing of information within the formation or in shifting between memory encoding and memory retrieval (Colgin and Moser, 2010). There is evidence that CA1 and CA3 preferentially synchronize at slow gamma $(25-50 \mathrm{~Hz})$ during exploration of a familiar environment (Colgin et al., 2009) and at fast gamma (65-100 Hz) during investigation of novel object-place pairs (Zheng et al., 2016a), suggesting that there may be distinct mechanisms that support band-specific CA3-CA1 coupling during different behavioral states. The tendency of the CA1 region to phase lock with either 
CA3 or the medial entorhinal cortex at distinct frequencies, but not both simultaneously, suggests that CA1 has selectivity features for different bands of gamma frequency input that can be differentially engaged (Colgin et al., 2009; Kemere et al., 2013). Here, we investigate the possibility that the CA1 region can transition between states that selectively facilitate its participation in synchronous activity at Schaffer collateral (SC) inputs in the slow or fast gamma range as circumstances require.

$\mathrm{SC}$ input from CA3 impinges on the proximal portion of the apical dendrites of CA1 pyramidal neurons, where signal integration is shaped by various potassium conductances. For example, the $\mathrm{Ca}^{2+}$-activated small conductance $\mathrm{K}^{+}$current $I_{\mathrm{SK}}$ links calcium dynamics in spines and dendrites to the afterhyperpolarization, thereby influencing the firing rate (Stocker et al., 1999; Pedarzani et al., 2005), whereas the A-type transient outward $\mathrm{K}^{+}$ current $I_{\mathrm{A}}$ has been shown to enhance compartmentalization of apical branches (Cash and Yuste, 1999). These channels are subject to cholinergic neuromodulation (Hoffman and Johnston, 1999; Buchanan et al., 2010; Giessel and Sabatini, 2010), which has previously been described as transiently reshaping neural circuitry (Hasselmo and Sarter, 2011; Atherton et al., 2015; Prado et al., 2017). Therefore, cholinergic activity may be an important determinant of signal integration in the hippocampal network, particularly when acetylcholine levels in the hippocampus are elevated, as is thought to occur in response to novelty (Acquas et al., 1996; Aloisi et al., 1997) or training on a new behavioral task (Teles-Grilo Ruivo et al., 2017).

We used a combination of computational modeling and in vitro slice electrophysiology to test the hypothesis that the intrinsic properties of CA1 pyramidal neurons prime them to "listen" to different bands of gamma frequency input from CA3 depending on physiological conditions. We applied trains of temporally precise gamma frequency inputs to CA1 pyramidal cells to investigate intrinsic mechanisms of frequency selectivity. We justify this form of stimulation with two pieces of evidence. First, during slow gamma oscillations $(40-50 \mathrm{~Hz})$ in anesthetized rats (FernándezRuiz et al., 2012), CA3 provides a regular, periodic drive to CA1 in vivo consisting of a "regular succession of pulse-like excitatory packages initiated by spontaneous clustered firing of CA3 pyramidal cells." Second, temporally precise input from CA3 to CA1 at slow gamma frequencies $(\sim 30 \mathrm{~Hz})$ was observed in carbacholinduced oscillations in vitro (Zemankovics et al., 2013).

We found that the proximal dendrites of CA1 neurons act as a kind of low-pass filter on the firing rate, restricting somatic firing preferentially to slow gamma frequencies in response to SC input; this tendency was reduced by apamin, carbachol, or oxotremorine-M (oxo-M), enhanced by $100 \mu \mathrm{M} \mathrm{BaCl}{ }_{2}$, and appears to be specific to SC inputs because it did not occur in response to somatic current injection. Mechanisms that allow neurons in CA1 to preferentially follow specific gamma bands may play a role in the routing or processing of information within the hippocampal formation.

\section{Materials and Methods}

Computational modeling. The multicompartmental model CA1 neuron of Bianchi et al. (2012), implemented in NEURON (RRID:SCR_005393), was used as a starting point. This model in turn was based on the Poirazi et al. (2003) model, with channel distributions and kinetics adjusted as in Shah et al. (2008). The multicompartmental model used in this study includes a leak current, two fast Hodgkin-Huxley-type $\mathrm{Na}^{+}$currents (somato-dendritic and axonal), a delayed rectifier, two A-type $\mathrm{K}^{+}$currents (proximal and distal), an $\mathrm{M}$-type $\mathrm{K}^{+}$current, a mixed conductance hyperpolarization-activated h-current, a T-type $\mathrm{Ca}^{2+}$ current, an R-type $\mathrm{Ca}^{2+}$ current, two L-type $\mathrm{Ca}^{2+}$ currents (somatic and dendritic), a slow
$\mathrm{Ca}^{2+}$-dependent $\mathrm{K}^{+}(\mathrm{SK})$ current and $\mathrm{Ca}^{2+}$ - and voltage-dependent $\mathrm{K}^{+}$(BK) current. The currents are distributed nonuniformly in the cases where experimental evidence supports it (Magee, 2016). In the Poirazi et al. (2003) model, the density of the $\mathrm{Ca}^{2+}$-dependent, voltageindependent $\mathrm{K}^{+}$current that we attribute to the SK channels as well as the density of the $\mathrm{Ca}^{2+}$-dependent, voltage-dependent $\mathrm{BK}$ current is greatly elevated in the apical dendrites between 50 and $200 \mu \mathrm{m}$ from the soma, the density of the L-type $\mathrm{Ca}^{2+}$ channels is elevated at distances $>50 \mu \mathrm{m}$ from the soma, and the T-type $\mathrm{Ca}^{2+}$ channel density is only nonzero at distances $>100 \mu \mathrm{m}$ from the soma. These features, which emphasize the effect of dendritic $\mathrm{Ca}^{2+}$ entry, were retained.

Here, we summarize the major modifications we made to the model of Bianchi et al. (2012). The model parameters were applied to a different cell morphology (cell pc2b; Megías et al. (2001)), which has 144 compartments (see Fig. 1A). Distance was calculated to reflect the actual path along the dendrite and the passive leak reversal was fixed at $-70 \mathrm{mV}$ throughout the neuron. To better capture the dynamics of the SK conductance, the time constant for the decay of calcium to its basal value was decreased and the steady-state half-activation of $\left[\mathrm{Ca}^{2+}\right]$ for the SK channel was decreased as well. The kinetics of the delayed rectifier were sped up at hyperpolarized potentials to limit the contribution of this current to the medium afterhyperpolarization. To more faithfully replicate the delay between an EPSP in the proximal dendrites and an action potential (AP) in the soma, the conductance density for $I_{\mathrm{h}}$ was reduced by a factor of 10. Also, the gradient for $I_{\mathrm{h}}$ was implemented as piecewise linear rather than sigmoidal and a gradient in the half-activation was also implemented (Magee, 1998). To reproduce the decrement in back-propagating spike amplitude with distance from the soma, the fast sodium conductance density was reduced from $0.042 \mathrm{~S} / \mathrm{cm}^{2}$ in the soma to 0.015 in the dendrites (Gasparini and Migliore, 2015). Conductance densities were also adjusted for the delayed rectifier, the A-type, $\mathrm{SK}$ and $\mathrm{BKK}^{+}$currents, and the T-type, L-type, and R-type $\mathrm{Ca}^{2+}$ currents. The specific capacitance was increased to 1.5 $\mu \mathrm{F} / \mathrm{cm}^{2}$ in the soma and apical dendrite. Axial and membrane resistivity were held constant in the apical dendrites.

Synaptic stimulation was modeled as activation of glutamatergic synapses at 20 locations along the apical trunk between 200 and $300 \mu \mathrm{m}$ from the soma and oblique dendrites that were attached to this portion of the apical trunk (see Fig. 1A). The AMPA synapses were modeled as biexponential conductances with rise time constants of 0.5 and $1 \mathrm{~ms}$. A two-state kinetic scheme Destexhe et al. (1995) was used for NMDA receptor dynamics, with the rate constants for binding and unbinding set to $0.35 \mathrm{~ms}^{-1}$ and $0.035 \mathrm{~ms}^{-1}$, respectively, and the voltage dependence of $\mathrm{Mg}^{2+}$ block from Jahr and Stevens (1990). The ratio of the AMPA and NMDA currents was set at 2 per McDermott et al. (2006).

Slice preparation. All experiments followed protocols approved by the Louisiana State University Health Sciences Center Institutional Animal Care and Use Committee and were in accordance with National Institutes of Health's guidelines on the use of laboratory animals in research. Seven- to 10-week-old male Sprague Dawley rats were deeply anesthetized via intraperitoneal injection of ketamine and xylazine (90 and 10 $\mathrm{mg} / \mathrm{kg}$, respectively). Once the toe pinch reflex ceased, rats were transcardially perfused with ice-cold oxygenated perfusion/cutting solution containing the following (in mM): $\mathrm{NaHCO}_{3} 28, \mathrm{KCl} 2.5, \mathrm{NaH}_{2} \mathrm{PO}_{4} 1.25$, $\mathrm{MgCl}_{2} 7, \mathrm{CaCl}_{2}$ 0.5, dextrose 7, sucrose 234, L-ascorbic acid 1, and sodium pyruvate 3 and decapitated. Brains were rapidly removed and 400$\mu \mathrm{M}$-thick transverse hippocampal slices were cut with a vibratome. Slices were transferred to an oxygenated external solution containing the following (in mM): $\mathrm{NaCl} 125, \mathrm{NaHCO}_{3} 25, \mathrm{KCl} 2.5, \mathrm{NaH}_{2} \mathrm{PO}_{4} 1.25, \mathrm{MgCl}_{2}$ $1, \mathrm{CaCl}_{2} 2$, dextrose 25 , ascorbate 1 , and sodium pyruvate 3 and allowed to recover for $1 \mathrm{~h}$ at $36^{\circ} \mathrm{C}$, followed by an additional recovery period at room temperature lasting at least $1 \mathrm{~h}$.

Patch-clamp electrophysiology. Slices were transferred to a recording chamber and superfused with external solution identical to that in the recovery chamber. All experiments were performed at $34-36^{\circ} \mathrm{C}$. CA1 pyramidal cells were identified via differential interference contrastinfrared video. Whole-cell current-clamp recordings were made with a Dagan BVC 700A amplifier in the active "bridge" mode. Recording pipettes had a resistance of $1-4 \mathrm{M} \Omega$ when filled with internal solution containing the following (in $\mathrm{mm}$ ): potassium methanesulphonate 125 , 
$\mathrm{KCl}$ 20, HEPES 10, $\mathrm{NaCl} 4, \mathrm{Mg}_{2}$ ATP 4, Tris 2 GTP 0.3, and phosphocreatine 14. Series resistance was monitored throughout the recordings and was usually $<20 \mathrm{M} \Omega$. Cells with resting membrane potentials depolarized beyond $-60 \mathrm{mV}$ were discarded.

Gabazine $(12.5 \mu \mathrm{M})$ and CGP55845 $(1 \mu \mathrm{M})$ were applied in the external solution in all experiments to block GABAergic neurotransmission; apamin (100 nM), $\mathrm{BaCl}_{2}(20$ or $100 \mu \mathrm{M})$, carbachol $(2 \mu \mathrm{M})$ or oxo-M $(0.2$ $\mu \mathrm{M})$ were added as needed. In two sets of experiments, $N$-(2,6dimethylphenylcarbamoylmethyl)triethylammonium (QX-314, $3 \mathrm{~mm}$ ) or apamin $(100 \mathrm{~nm})$ was added to the internal solution in the patch pipette rather than the external solution to block channels in the postsynaptic cell exclusively. In another set of experiments,1,2-Bis(2aminophenoxy)ethane- $\mathrm{N}, \mathrm{N}, \mathrm{N}^{\prime}, \mathrm{N}^{\prime}$-tetraacetic acid (BAPTA, $5 \mathrm{~mm}$ ), or 1,2-Bis(2-aminophenoxy)ethane- $\mathrm{N}, \mathrm{N}, \mathrm{N}^{\prime}, \mathrm{N}^{\prime}$-tetraacetic acid tetrapotassium salt (BAPTA-tetrapotassium salt, $5 \mathrm{~mm}$ ) were added to the pipette solution to chelate intracellular $\mathrm{Ca}^{2+}$. When BAPTA-tetrapotassium salt was used, the concentration of potassium methanesulfonate was reduced to $110 \mathrm{~mm}$ to adjust osmolarity. Gabazine and CGP55845 were purchased from Abcam; apamin from Alomone Labs; QX-314, $\mathrm{BaCl}_{2}$, and BAPTAtetrapotassium salt from Sigma-Aldrich; carbachol and oxo-M from Tocris Bioscience; and BAPTA from Cayman Chemical.

Electrical stimulation. Electrical stimulation of SCs was achieved via current pulses delivered through a bipolar tungsten electrode (A-M Systems) placed in stratum radiatum $\sim 200-250 \mu \mathrm{M}$ from the pyramidal cell layer. The stimulation intensity was set so that the cell fired reliably to a train of 10 current pulses at $25 \mathrm{~ms}$ intervals $(40 \mathrm{~Hz})$ in every experimental condition. The stimulation intensity was therefore adjusted between control conditions and pharmacological treatment in Figures 5, 6, 7, and 8. In the case of carbachol (see Fig. 8), this experimental design allowed us to focus on the intrinsic postsynaptic effects of acetylcholine rather than the effects on NMDA receptors (Markram and Segal, 1990) and presynaptic glutamate release at CA3-CA1 synapses (Hasselmo and Schnell, 1994). In one set of experiments, somatic current injection was used instead of electrical stimulation of the afferent fibers. In this case, $2 \mathrm{~ms}$ pulses were delivered to the soma through the recording pipette with a current amplitude (between 0.5 and $2 \mathrm{nA}$ ) that elicited a single AP reliably 3 times in a row.

Experimental design and statistical analyses. Experimental data were recorded and analyzed with IGOR Pro software (WaveMetrics, RRID: SCR_000325) and are presented as means \pm SEM. The number of cells recorded in each experiment is indicated in the Results section. A typical patch-clamp electrophysiology experiment with a difference in means of $1.3-2 \times$ and a SD of $0.2-0.3$ requires $n=6-12$ for $p=0.05$ and a power of 0.9 (Cohen, 1977); each experimental group in this study is made up of $n \geq 7$ recording sessions. In most cases, recordings were from one cell per animal. The notable exceptions were 10 cells recorded from four animals in the "subthreshold stimulation" group and nine cells recorded from three animals with QX-314 in the recording pipette (see Figure $4 B$ and $D$, respectively.

The ability of a cell to follow a given input frequency was evaluated as the number of times it fired in response to 10 pulse trains. For these data, statistical analyses were performed in SPSS (IBM, RRID:SCR_002865) using the tutorials and software guide from Laerd Statistics (2015, Statistical tutorials and software guides; https://statistics.laerd.com/). Parametric analyses (repeated-measures ANOVA and paired-samples $t$ test) were used when data were normally distributed as determined by the Shapiro-Wilk test for normality. The corresponding nonparametric analyses (Friedman test, Wilcoxon signed-rank test, and sign test) were used when data were not normally distributed and/or contained outliers as assessed by boxplots in SPSS. The sign test was used when data were not symmetrically distributed, which is a critical requirement for the Wilcoxon signed-rank test. Where possible, comparisons were made in the same cell before and after pharmacological treatment using the above tests as appropriate for paired data. Otherwise, the Mann-Whitney $U$ test for unpaired data was used to make comparisons between different groups of cells. Significant differences revealed by repeated-measures ANOVA or the Friedman test were followed up by post hoc analyses using Bonferroni-corrected pairwise comparisons.
The interspike intervals (ISIs) were used to quantify firing at slow or fast gamma in response to different frequency inputs. For these data, differences between the distributions of ISIs were compared via the twosample Kolmogorov-Smirnov test, which was used to obtain maximum difference $(D)$ values and corresponding $p$-values.

Phase locking for three sample frequencies $(40,70$, and $100 \mathrm{~Hz})$ was quantified by calculating the vector strength $(r)$ as follows: the latency (calculated as the interval between stimulation and the membrane potential crossing $-40 \mathrm{mV}$ ) was normalized to the interstimulation period and converted to a phase (angle), specifying a point on the unit circle, where the unit circle represents a single cycle of the stimulation frequency. The phase for each spike $\left(\theta_{\mathrm{i}}\right)$ was then used to calculate the vector strength for each of the analyzed frequencies according to the following equation:

$$
r=\sqrt{\frac{1}{n}\left(\sum_{i=1}^{n} \cos \left(\theta_{i}\right)\right)^{2}+\frac{1}{n}\left(\sum_{i=1}^{n} \sin \left(\theta_{i}\right)\right)^{2}}
$$

For circular statistics, the data from all neurons in a group were pooled at each stimulation frequency. The circular statistics package in R (CRAN, RRID:SCR_003005) was used to implement the Rayleigh test for the null hypothesis of uniformity (Watson and Williams, 1956). The Wallraff test for differences in vector strength, which is a measure of concentration, is described in Pewsey et al. (2013) and applies the nonparametric ANOVA Kruskal-Wallis rank-sum test to the set of absolute values of the difference of each phase from the mean value at each frequency, with the null hypothesis that the median of the distributions from which the datasets were drawn is the same. The confidence intervals were estimated using the large sample distribution estimate of the mean vector strength of a circular distribution (Pewsey, 2004). Polar plots were generated using rose.diag in $\mathrm{R}$ and the area of each of the 16 sectors is proportional to the number of phases that fell in each bin.

Differences were considered to be statistically significant when $p<$ 0.05 . When the $p$-value is reported as "exact," it is based on the binomial distribution rather than an approximation of the binomial distribution, so no other test statistic is reported.

\section{Results}

Input location and potassium conductance in multicompartmental model of CA1 pyramidal neuron confer frequency selectivity

We simulated temporally precise CA3 excitatory input to the morphologically realistic model CA1 pyramidal neuron (Fig. $1 A$ ) by simultaneously activating 20 excitatory synapses (red dots) on the apical trunk and obliques at different gamma frequencies. For comparison, somatic stimulation was modeled by simulating trains of 2 ms current injection steps at the soma. In response to synaptic activation in the proximal apical dendrite, the model neuron fired at $40 \mathrm{~Hz}$ when the input was at $40 \mathrm{~Hz}$ (Fig. 1B1). This response frequency dropped off dramatically when the input was applied at $100 \mathrm{~Hz}$ such that the output frequency was essentially at $50 \mathrm{~Hz}$. Therefore, in response to input at the apical dendritic compartment, the model CA1 neuron fired at slow gamma frequencies regardless of whether the input frequency was at slow or fast gamma. Conversely, when somatic stimulation was applied (Fig. 1C), the output matched the input in a 1:1 relationship at both slow gamma and fast gamma.

In a number of cell types, the small conductance (SK) calcium activated potassium current influences the firing pattern via the afterhyperpolarizing potential (Bond et al., 2005; Higgs and Spain, 2009). In CA1 pyramidal neurons, in particular, SK channel activation by the transient influx of calcium associated with depolarization contributes to the medium afterhyperpolarization, restricting a cell's ability to fire again immediately after an AP (Stocker et al., 1999; Pedarzani et al., 2005). At slow gamma 
A

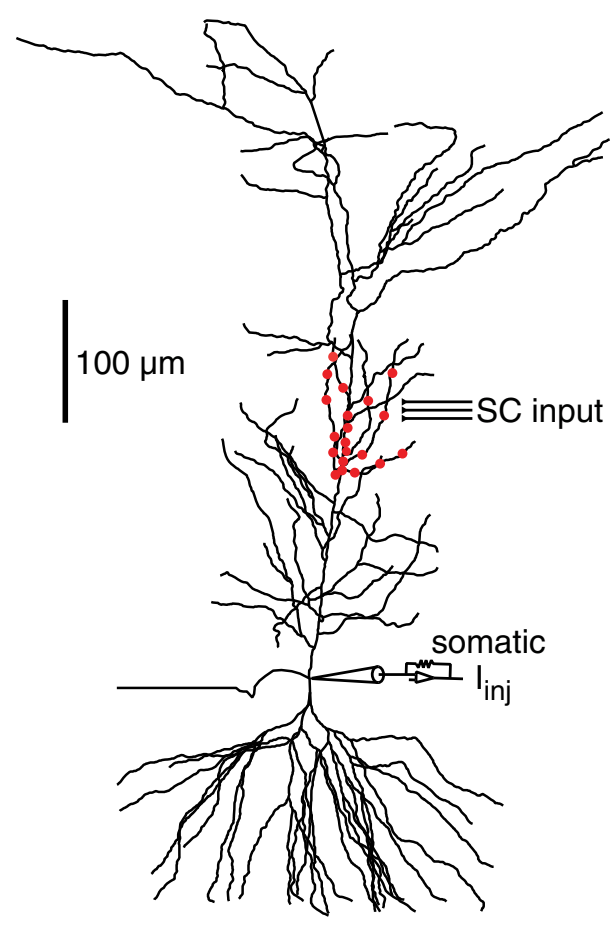

B1 synaptic stimulation $40 \mathrm{~Hz} \quad 100 \mathrm{~Hz}$

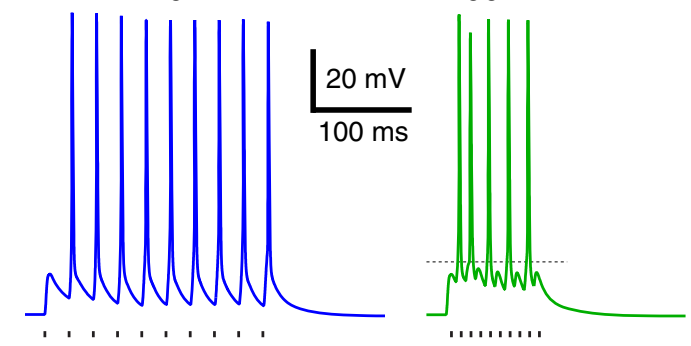

B2 $\left[\mathrm{Ca}^{2+}\right]_{\mathrm{i}}$ $-40 \mathrm{~Hz}$ (syn)
$-100 \mathrm{~Hz}($ syn)
$-100 \mathrm{~Hz}\left(\right.$ I $\left._{\text {inj }}\right)$
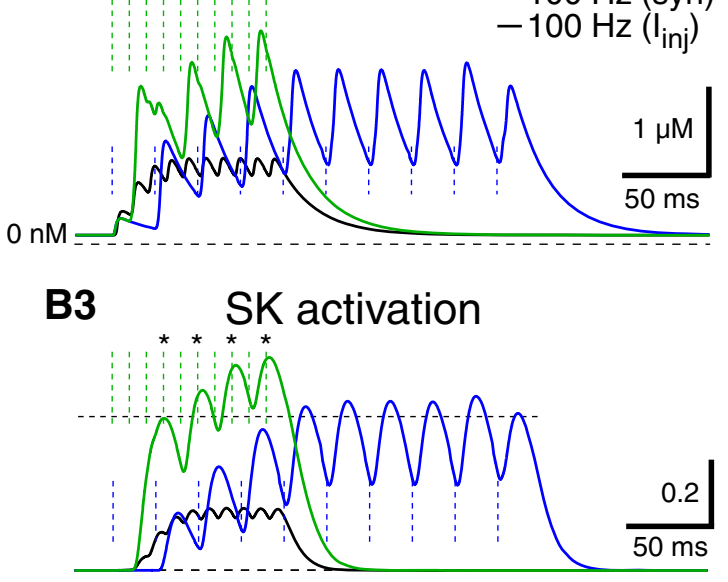

D SK current removed (synaptic stimulation)

$40 \mathrm{~Hz}$

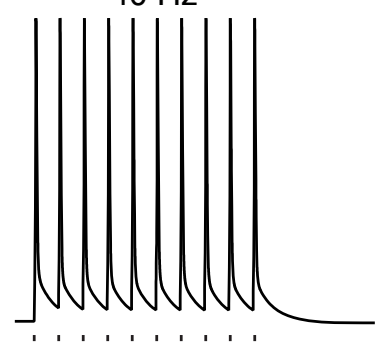

$100 \mathrm{~Hz}$

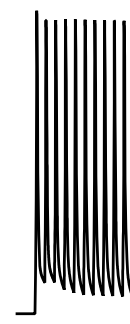

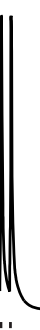

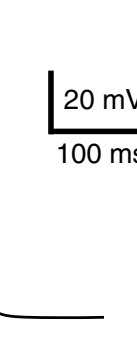

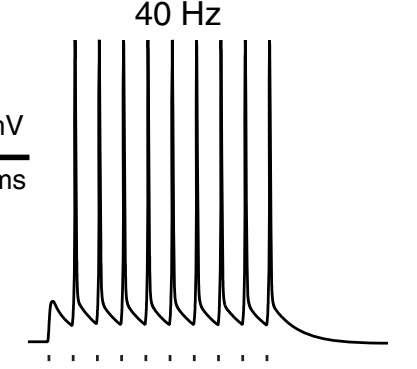

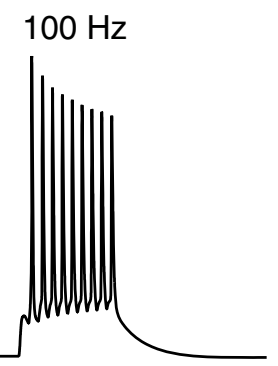

Figure 1. The model CA1 pyramidal neuron responds preferentially to lower frequencies in response to proximal stimulation, but is not selective in response to somatic stimulation. $A$, Morphology of p 2 B (Megías et al., 2001) with approximate positions of simulated input at either the proximal apical dendrite (20 locations in the trunk and oblique branches) to simulate SC input (red dots) or at the somatic compartment of the model neuron to simulate somatic current injection $\left(l_{\text {inj }}\right)$. B1, Model output in response to repetitive activation of proximal synapses at 40 and $100 \mathrm{~Hz}$. Stimulus inputs are indicated below voltage traces with tick marks. The model output is $40 \mathrm{~Hz}$ in response to $40 \mathrm{~Hz}$ proximal input, as can be seen by 1:1 correspondence between tick marks and APs. In response to $100 \mathrm{~Hz}$ proximal input, the model output is $50 \mathrm{~Hz}$, as can be seen by 2:1 correspondence between tick marks and APs. B2, Free $\left[\mathrm{Ca}^{2+}\right]_{i}$ in the most proximal dendritic compartment receiving synaptic activation for both $40 \mathrm{~Hz}$ (blue trace) and $100 \mathrm{~Hz}$ (green trace). The vertical dashed lines represent the timing of the synaptic activation at the respective frequencies and the dashed horizontal line represents $0 \mathrm{~nm}$. B3, Values of the activation gating variable for the $S K$ current at the point of stimulation in the same compartment as $\boldsymbol{B}$. Asterisks represent the missed spikes, which correspond to higher SK activation (above the threshold represented by the upper horizontal dashed line). The ninth stimulus at $100 \mathrm{~Hz}$ falls above the threshold, yet there is no missed spike; therefore, although this "threshold" is helpful to understanding the mechanism, it is only approximate because a single state variable in a single compartment does not capture the full state of the model. C, Model output in response to repetitive stimulation of the somatic compartment at 40 and $100 \mathrm{~Hz}$. The model fires with 1:1 correspondence whether the input is at slow ( $40 \mathrm{~Hz}$ ) or fast ( 100 $\mathrm{Hz}$ ) gamma. $\boldsymbol{D}$, Removal of SK conductance from model abolishes selectivity for low frequencies of synaptic stimulation. Model demonstrates 1:1 input:output relationship without this conductance whether the input is at slow or fast gamma.

frequencies, stimulus-associated $\left[\mathrm{Ca}^{2+}\right]_{\mathrm{i}}$ (Fig. 1B2, blue trace) always decays to levels that do not sufficiently activate SK channels (Fig. 1B3, blue trace) to suppress spiking; the blue vertical dashed lines indicating the stimulation times occur at the troughs of these waveforms. Conversely, when activating synapses to simulate the SC input to the model neuron at $100 \mathrm{~Hz}$, higher levels of $\left[\mathrm{Ca}^{2+}\right]_{\mathrm{i}}$ and SK current activation (Fig. $1 B 2, B 3$, green traces) are achieved in the proximal dendrites. Stimuli that are delivered above a certain threshold of SK activation (dashed horizontal line in Fig. 1B3) do not evoke an AP (indicated by asterisks). Indeed, when we set the SK conductance to zero and stimulated the proximal glutamatergic synapses in the model neuron, the afterhyperpolarization between spikes was decreased and the input:output relationship relaxed to 1:1 for both slow and fast gamma stimu- 


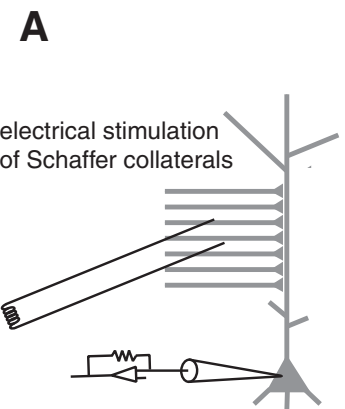

C

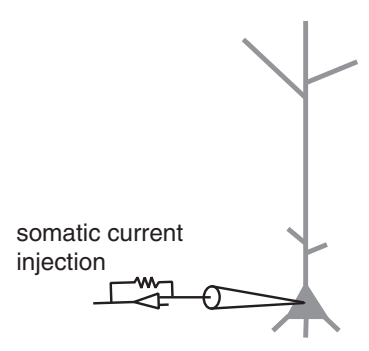

B

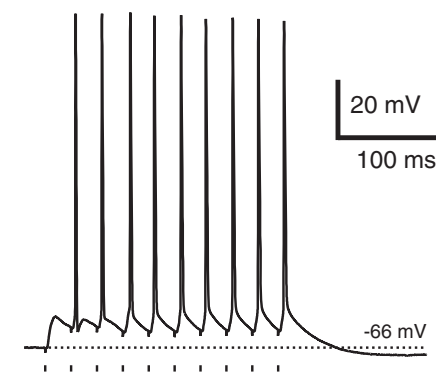

Schaffer collateral stimulation

$70 \mathrm{~Hz}$

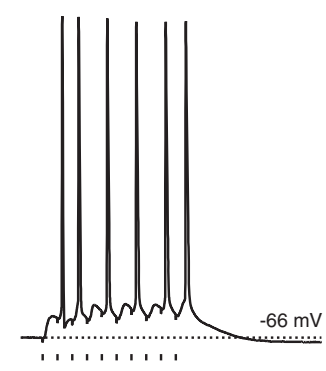

$100 \mathrm{~Hz}$

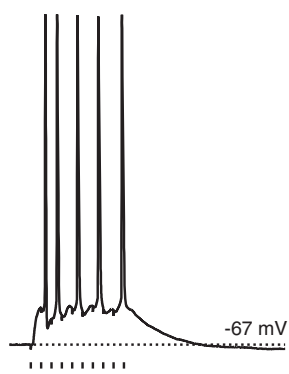

D

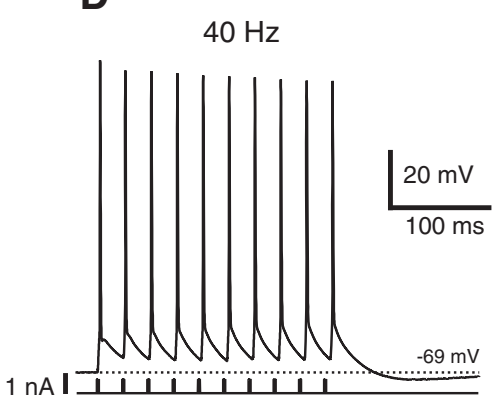

somatic current injection $70 \mathrm{~Hz}$

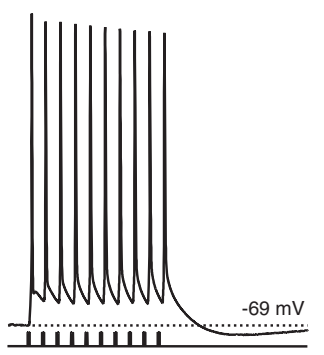

$100 \mathrm{~Hz}$

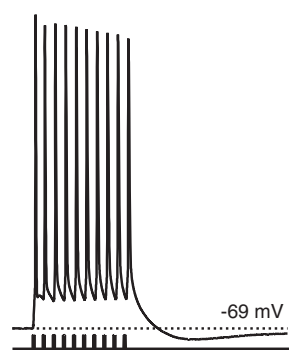

Figure 2. CA1 pyramidal cells fire at slow gamma in response to fast gamma SC input, but lack frequency selectivity in response to somatic current injection. $A$, Schematic indicating experimental configuration for SC stimulation. $\boldsymbol{B}$, Representative traces of a neuron firing in response to SC stimulation at different gamma frequencies. The timing of the stimulus inputs is indicated below the voltage traces with tick marks. The cell reliably followed the 10 pulse input train at slow $(40 \mathrm{~Hz})$, but not fast $(70$ and $100 \mathrm{~Hz})$ gamma. C, Schematic indicating experimental configuration for somatic current injection. $\boldsymbol{D}$, Representative traces of a neuron firing in response to somatic current injection at different gamma frequencies. Somatic current injection is indicated by current traces below voltage traces. The cell fired in response to every input at slow $(40 \mathrm{~Hz})$ and fast $(70 \mathrm{and} 100 \mathrm{~Hz})$ gamma.

lation frequencies (Fig. 1D). Therefore, for skipped spikes, the activation of the SK channels in the proximal dendrite attenuates the EPSP below the threshold for AP initiation (see horizontal dashed line in Fig. 1B1, right). In contrast, depolarizing current pulses applied at the soma adjacent to the axonal site of AP initiation are not substantially attenuated by activation of dendritic SK channels by back-propagating APs (Fig. 1B2,B3, black traces).

Therefore, the model predicts that CA1 neurons are better able to follow SC stimulation in the slow gamma range compared with fast gamma frequencies. According to the simulations, this feature is specific to the SC input and depends to some degree on a potassium conductance associated with SK channels. These results suggest the interesting scenario that amplification or reduction of this current could be a means by which the firing frequency of CA1 pyramidal neurons in response to CA3 input is modulated.

\section{In vitro, CA1 pyramidal neurons reliably follow slow, but not fast, gamma input at SCs}

The model predicted that SC input to CA1 pyramidal neurons preferentially elicits slow gamma frequency spiking. To test this we performed in vitro experiments in hippocampal slices, delivering trains of stimulation to the stratum radiatum at discrete frequencies across the range of gamma and recording the responses at the somata of CA1 pyramidal neurons. In parallel experiments, we delivered stimulation as trains of current pulses injected at the soma via the recording electrode; schematic illustrations of the two experimental stimulation protocols are shown in Figure 2, $A$ and $C$. For this study, all in vitro control conditions include superfusion of $\mathrm{GABA}_{\mathrm{A}}$ and $\mathrm{GABA}_{\mathrm{B}}$ block- ers (gabazine, $12.5 \mu \mathrm{M}$ and CGP55845, $1 \mu \mathrm{M}$, respectively) in the external solution.

Qualitatively, the response to different frequency input (40, 70 , and $100 \mathrm{~Hz}$ ) for SC stimulation can be seen in the voltage traces in Figure $2 B$. The stimulation intensity was initially calibrated so that, at $40 \mathrm{~Hz}$, the cell reliably fired in response to each input after the first one in a 10 pulse train. At 70 and $100 \mathrm{~Hz}$, the cell only fired in response to every other input, effectively firing at half the input frequency. In response to $40 \mathrm{~Hz}$ stimulation, cells fired an average of $8.8 \pm 0.1$ spikes, $6.2 \pm 0.2$ spikes in response to $70 \mathrm{~Hz}$ stimulation, and $5.3 \pm 0.1$ spikes at $100 \mathrm{~Hz}$ stimulation. We performed repeated-measures ANOVA on the number of APs elicited by the 10-pulse trains and found that it differed significantly for the three input frequencies $\left(F_{(1.470,22.053)}=252.321\right.$, $p<0.0005, n=16$ ). Bonferroni-corrected pairwise comparisons indicated that this difference was significant between all three frequencies (40 versus $70 \mathrm{~Hz}, p<0.0005$; 40 vs $100 \mathrm{~Hz}, p<$ $0.0005 ; 70$ vs $100 \mathrm{~Hz}, p<0.0005)$. Therefore, the CA3 input that faithfully elicits slow gamma frequency output in CA1 neurons does not generate fast gamma firing.

In contrast to synaptic input at the SCs, the example in Figure $2 D$ shows that, when current pulses were injected to the soma via the recording electrode at 40,70, and $100 \mathrm{~Hz}$, the cell fired at every input both at slow and fast gamma frequencies $(9.9 \pm 0.1$ spikes at $40 \mathrm{~Hz}, 9.8 \pm 0.2$ at $70 \mathrm{~Hz}$, and $9.2 \pm 0.3$ at $100 \mathrm{~Hz}$ ). The Friedman test (used because the data were not normally distributed) indicated a significant difference in the numbers of APs fired $\left(\chi_{(2)}^{2}=9.500, p=0.009, n=10\right)$, but this was not detected by post hoc analysis ( $40 \mathrm{vs} 70 \mathrm{~Hz}, p=1.000$; $40 \mathrm{vs} 100 \mathrm{~Hz}, p=$ $0.221 ; 70$ vs $100 \mathrm{~Hz}, p=0.353)$. 
To illustrate the input:output relationships across gamma frequencies, we constructed heat maps of the output frequency as a function of the input frequency for the pooled data for all of the neurons firing in response to SC stimulation (Fig. $3 A, n=16$ ) or somatic current injection (Fig. $3 B, n=10$ ). Dashed lines indicate where the data would fall if the input:output relationship were locked $1: 1$ or $2: 1$. When cells were stimulated via SC inputs, the relationship was close to $1: 1$ for frequencies up to $50 \mathrm{~Hz}$, dropping to 2:1 at input frequencies above $60 \mathrm{~Hz}$ (Fig. 3A). These data indicate that the breakdown of the neurons' ability to fire at the input frequency arises at the border between slow gamma (25-50 $\mathrm{Hz})$ and fast gamma $(65-100 \mathrm{~Hz})$, which is an interesting finding considering the tendency of CA1 to synchronize with CA3 at slow gamma in certain circumstances in vivo (Colgin et al., 2009; Kemere et al., 2013). In addition, that the cells are able to reliably follow slow but not fast gamma input supports the model predictions. As in the model, this restriction on the output frequency appears to be selectively triggered by activation of the SC input because we found that brief $(2 \mathrm{~ms})$ current injection at the soma generated a 1:1 input:output relationship throughout the range of gamma (Fig. 3B).

To quantify the tendency to fire at slow gamma in response to repetitive SC stimulation, we measured the ISIs and plotted their distribution at 40,70, and $100 \mathrm{~Hz}$ for all of the neurons examined. For SC stimulation (Fig. 3C), the ISI distribution for $40 \mathrm{~Hz}$ was clustered around $25 \mathrm{~ms}$. When the stimulation frequency was at $70 \mathrm{~Hz}$, the ISI distribution developed two peaks, one around 15 $\mathrm{ms}$ and the other around $28 \mathrm{~ms}$. In response to $100 \mathrm{~Hz}$ stimulation, a similar phenomenon occurred: two peaks developed, one reflecting the cells firing at the input frequency and the other corresponding to half of the input frequency. In contrast, when stimulation was delivered as current pulses injected at the soma (Fig. 3D), the ISI distribution was narrow for all input frequencies and the vast majority of ISIs were restricted to single bins corresponding to the input frequency. The cumulative distributions of ISIs are shown (Fig. 3D, insets) for cells stimulated at SCs (Fig. 3D, black lines) and via somatic current injection (Fig. 3D, gray lines) above the corresponding somatic current injection histograms. SC stimulation and somatic current injection generated significantly different distributions, as compared by the Kolmogorov-Smirnov test, for 40, 70, and $100 \mathrm{~Hz}$ stimulation $(D=0.524,0.886$, and 0.901 , respectively; associated $p$-values $<0.0005$ in each comparison).

To quantify the precision of phase locking at the various frequencies, we calculated the vector strength $r$ (see Materials and Methods), a number between 0 and 1 that correlates with the degree of synchronization between input and output ( 0 for no synchronization, 1 for perfect synchronization). The distribution of the phases and the vector strength for the various frequencies are represented as polar plots in insets in Figure $3 C$ for synaptic stimulation and in Figure $3 D$ for somatic current injection. We used the Rayleigh test to estimate the level of uniformity of the phases of the spikes at each frequency. The $p$-value for the Rayleigh test using the phases of spikes within the cycle of the stimulation frequency was effectively zero $(p \ll 0.000001)$ at all three frequencies, so the null hypothesis of uniform distribution around a circle can be rejected; there was significant phase locking at all stimulus frequencies. The vector strengths, $r$ (represented by the red line in the polar plots), from the cumulative data across all neurons stimulated at SC were 0.925 (0.916$0.934)$ at $40 \mathrm{~Hz}, 0.782(0.756-0.808)$ at $70 \mathrm{~Hz}$, and $0.622(0.585-$ $0.660)$ at $100 \mathrm{~Hz}$. The $95 \%$ confidence intervals (95\% CIs) are given in parentheses after the vector strength at the three frequen- cies. Note that the $95 \%$ CIs do not overlap, indicating that the differences are significant. Moreover, the Wallraff test also rejected the null hypothesis of equal vector strength at 40,70 , and $100 \mathrm{~Hz}$ with $p<0.000005$. These results suggest that, although there is significant phase locking at all of the frequencies examined, CA1 pyramidal neurons are better able to phase lock to temporally precise SC input at slow, rather than fast, gamma frequencies. Conversely, for somatic stimulation, the vector strengths, $r$, from the cumulative data across all neurons were $0.997(0.997-0.998)$ at $40 \mathrm{~Hz}, 0.897(0.857-0.938)$ at $70 \mathrm{~Hz}$, and $0.964(0.959-0.969)$ at $100 \mathrm{~Hz}$.

The above data demonstrate that, in response to SC stimulation at frequencies across the range of gamma, CA1 pyramidal neurons tend to fire more reliably at slow gamma regardless of the input frequency. Conversely, in response to somatic current injection, CA1 pyramidal neurons fire at every input without selectivity for any frequency range. This provides evidence that sodium channel inactivation in the postsynaptic neuron does not underlie the frequency restriction and suggests instead that it is specific to the SC input.

To test whether these differences were specific to the intensity of synaptic stimulation chosen, we performed the same analysis after increasing the intensity of stimulation; results are summarized in Table 1 . When the stimulation intensity was increased, cells fired more APs than they did at baseline, but the relationship between frequencies persisted. Repeated-measures ANOVA confirmed significant differences in the numbers of APs due to input frequency (Table $1, n=12$ ) whether examined at baseline $\left(F_{(2,22)}=389.906, p<0.0005\right)$, at $20 \%$ increase in stimulation intensity $\left(F_{(1.216,13.381)}=96.180, p<0.0005\right)$, or at $30 \%$ increase in stimulation intensity $\left(F_{(1.362,14.978)}=93.216, p<0.0005\right)$. The vector strength did improve somewhat for stronger stimulations, but it was only significantly different for increases of $20 \%$ at 40 and $70 \mathrm{~Hz}$ and did not increase significantly as the stimulation intensity was increased from $20 \%$ to $30 \%$. Moreover, phase locking remained better for slow gamma frequency input than for fast gamma frequency input (Table 1). When we increased the intensity of stimulation by $40 \%$ or more, most neurons started firing more than one AP per stimulation, confounding our measures of spike responses to precise periodic inputs.

\section{Synaptic depression does not play a role in frequency selectivity at SC inputs}

To determine whether the inability to fire at fast gamma frequencies is dependent on a presynaptic mechanism (i.e., short-term synaptic depression) at higher frequencies, we recorded the membrane potential profile in the absence of postsynaptic APs across trains of 40, 70, and $100 \mathrm{~Hz}$ SC input (see example traces in Fig. $4 A, C$ ). The responses were measured as the difference between baseline and the maximum amplitude of each EPSP following the synaptic input. The plots in Figure 4 are averaged membrane potential responses to 10-pulse trains of synaptic stimulation that were either subthreshold (Fig. $4 B, n=10$ ) or delivered in the presence of QX-314 (3 mM), a membraneimpermeable, voltage-sensitive $\mathrm{Na}^{+}$channel blocker (Fig. $4 D$, $n=9$ ). QX-314 was applied intracellularly to prevent spikes to evoke larger responses comparable to those evoked by the stimulation intensities in the experiments in Figure 2. In both conditions, there was a consistent increase in EPSP amplitude as the stimulus train progressed, particularly at fast gamma input. From the shape of the waveforms, dominated as they are by summation, there is no evidence that the synaptic response dips during the stimulus train in a manner that would account for the cells 

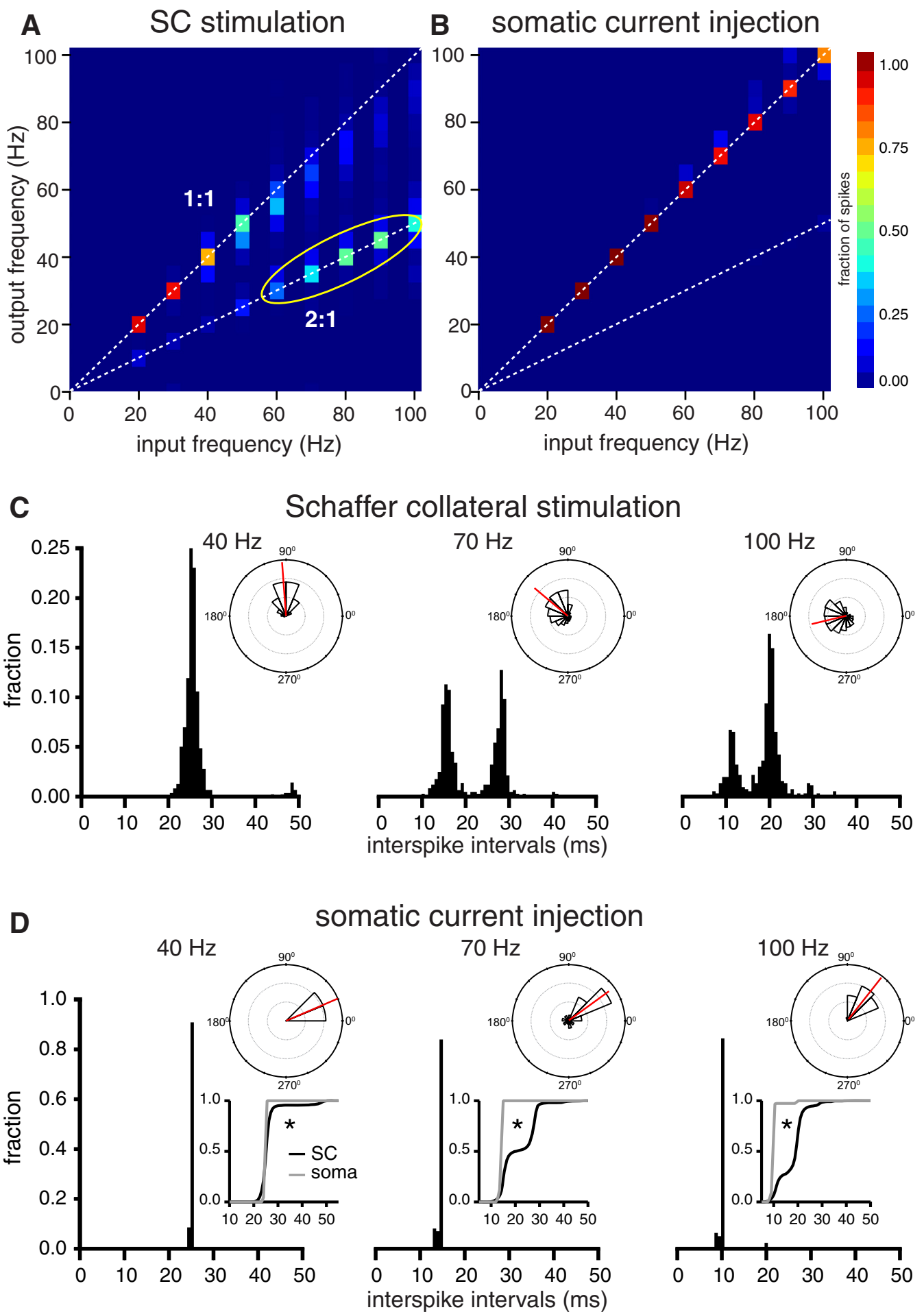

Figure 3. Input:output relationships demonstrate frequency selectivity at $S C$ but not somatic inputs. $A, B$, Heat map representations of output frequency as a function of input frequency for the pooled data of all the cells stimulated at SC $(n=16 ; \boldsymbol{A})$ or through somatic current injection $(n=10 ; \boldsymbol{B})$. Dashed lines correspond to 1:1 and 2:1 input:output relationships. In response to SC stimulation, the hottest output frequencies are at $60 \mathrm{~Hz}$ and below regardless of the input frequency. For input frequencies $>60 \mathrm{~Hz}$, the input:output relationship drops from 1:1 to 2:1, as highlighted by the yellow ellipse. When current pulses are injected to the soma, the input:output relationship remains 1:1 at all gamma frequencies. C, ISI distributions in response to SC stimulation at different gamma frequencies. At $40 \mathrm{~Hz}$ stimulation, ISI distribution is grouped around the interval that corresponds to the stimulation frequency, but at fast gamma frequencies (70 and $100 \mathrm{~Hz})$, the ISI distribution shows two peaks; the smaller peak corresponds to the fast gamma frequency at which the cells were stimulated and the larger peak corresponds to half that frequency. Polar plots (insets) show the distribution of firing phase at the various frequencies. The vector strength $(r)$ is represented as a red line. Note that, with increasing frequency stimulation, the firing phase is more broadly distributed and the vector strength is smaller. $\boldsymbol{D}$, ISI distributions in response to somatic current injection across the range of gamma frequencies. ISI distribution shows one narrow peak in response to all input frequencies. The upper insets show the polar plots as in C; the lower insets show the cumulative distributions of ISIs for synaptic activation at SC (black lines) and somatic current injection (gray lines) at the respective frequencies. $x$-axes, ISI (in ms); $y$-axes, cumulative fraction of ISIs. Asterisks indicate significant differences in the cumulative distributions. 


\begin{tabular}{|c|c|c|c|c|c|c|}
\hline \multirow[b]{3}{*}{ Stimulation frequency $(\mathrm{Hz})$} & \multirow{2}{*}{\multicolumn{2}{|c|}{ Baseline }} & \multicolumn{4}{|l|}{ Increase } \\
\hline & & & \multicolumn{2}{|l|}{$20 \%$} & \multicolumn{2}{|l|}{$30 \%$} \\
\hline & No. of APs & $r$ value $(95 \% \mathrm{Cl})$ & No. of APs & $r$ value $(95 \% \mathrm{Cl})$ & No. of APs & $r$ value $(95 \% \mathrm{Cl})$ \\
\hline 70 & $7.0 \pm 0.2^{* * *}$ & $0.679(0.650-0.708)$ & $8.7 \pm 0.3^{* *}$ & $0.740(0.715-0.765)$ & $9.1 \pm 0.2^{*}$ & $0.776(0.752-0.801)$ \\
\hline 100 & $5.5 \pm 0.1^{* * *}$ & $0.515(0.473-0.557)$ & $7.0 \pm 0.2^{* * *}$ & $0.548(0.511-0.585)$ & $7.2 \pm 0.3^{* * *}$ & $0.585(0.550-0.621)$ \\
\hline
\end{tabular}

Number of action potentials (APs) and vector strength $r$ (with $95 \%$ Cl) for experiments with increasing stimulation intensity are given for trains of 10 stimuli applied at three different frequencies. Significance levels refer to difference with respect to $40 \mathrm{~Hz}$ stimulation. ${ }^{*} p=0.038,{ }^{* *} p=0.016,{ }^{* * *} p<0.0005$. For the difference between $70 \mathrm{~Hz}$ and $100 \mathrm{~Hz}$, $p$ was always $<0.0005$.

skipping every other input at 70 or $100 \mathrm{~Hz}$. This result suggests that we can rule out a presynaptic release mechanism for the firing rate frequency restriction at SC inputs. Model simulations reproduced the trend of the experimental data when the $\mathrm{Na}^{+}$ conductance was set to zero, replicating the effect of QX-314 (see red traces in Fig. 4D).

\section{SK and A-type potassium conductances have opposing effects on CA1 pyramidal neurons' ability to follow fast gamma}

The apical dendrites of CA1 pyramidal neurons are endowed with various conductances that confer active properties, such as compartmentalization of signal integration and varying integrative and output modes (Johnston et al., 1996; Golding et al., 1999; Gasparini and Magee, 2006). Having found that the tendency to fire at slow but not fast gamma is engaged at SC but not somatic inputs, we next investigated possible dendritic mechanisms that could underlie this apparent compartment-dependent frequency selectivity.

Work with the model during calibration had suggested involvement of the SK current in setting up the observed preference for slow gamma firing (Fig. 1D). In adult rat CA1 pyramidal neurons, this current is carried by SK2 channels, the expression of which, primarily in spines, increases along apical dendrites with distance from the soma (Ballesteros-Merino et al., 2012). SK channels are activated by intracellular calcium elevation via voltage-gated calcium channels or NMDA receptors (Ngo-Anh et al., 2005; Bloodgood and Sabatini, 2007; Wang et al., 2014). During depolarization, this current serves to deepen the medium afterhyperpolarization, limiting repetitive firing (Stocker et al., 1999; Pedarzani et al., 2005). We measured AP output in response to trains of 10 stimuli at SCs at different gamma frequencies before and after the addition of $100 \mathrm{~nm}$ apamin, a selective blocker of SK channels (Blatz and Magleby, 1986). An example experiment is shown in Figure 5. A cell in control conditions fires reliably at $40 \mathrm{~Hz}$, misses some inputs at $70 \mathrm{~Hz}$, and misses every other input at $100 \mathrm{~Hz}$ (Fig. 5A). In the presence of apamin, that same cell follows 70 and $100 \mathrm{~Hz}$ stimulation more accurately (Fig. $5 B)$. At stimulus intensities that generated $8.8 \pm 0.1 \mathrm{APs}$ at $40 \mathrm{~Hz}$ in control and $9.1 \pm 0.1$ in apamin (exact $p=0.125$, sign test, $n=$ 10), we saw significant increases at 70 and $100 \mathrm{~Hz}$ in apamin compared with control. The number of APs generated by $70 \mathrm{~Hz}$ input significantly increased from $6.8 \pm 0.2$ under control conditions to $8.0 \pm 0.3$ in the presence of external apamin (exact $p=$ 0.002 ). Likewise, the number of APs generated by $100 \mathrm{~Hz}$ input significantly increased from $5.5 \pm 0.2$ in control to $6.7 \pm 0.3$ in apamin (exact $p=0.002$ ).

Because apamin-sensitive SK channels have been identified in axon terminals of cultured hippocampal neurons (Obermair et al., 2003) and could therefore mediate an apamin-sensitive effect at the presynaptic level, we repeated these experiments while selectively blocking SK channels on the postsynaptic neurons. This was done by applying $100 \mathrm{~nm}$ apamin in the patch pipette instead of the external solution (Bock and Stuart, 2014). Because the drug dialyzed rather quickly into the cells, it was not possible to obtain full control datasets before and after intracellular apamin. Unpaired comparisons were therefore made to the bath-applied apamin group from the previous experiment discussed above to determine whether there was a significant difference between the application methods using the Mann-Whitney test. Apamin applied via the patch pipette $(n=8)$ had effects similar to externally applied apamin, as example traces show in Figure $5 C$. There were no significant differences in the number of APs between intracellularly applied apamin $(9.0 \pm 0.1$ spikes at $40 \mathrm{~Hz}, p=1.00, U=$ $40.0 ; 8.4 \pm 0.3$ spikes at $70 \mathrm{~Hz}, p=0.408, U=49.5 ; 6.5 \pm 0.3$ spikes at $100 \mathrm{~Hz}, p=0.633, U=34.5$; using an exact sampling distribution for $U$ ) and bath applied apamin (see previous paragraph), indicating that the effect seen was due to SK channel block on the postsynaptic cells. However, neither externally or internally applied apamin reversed the increased precision at lower frequency stimulation; vector strengths for extracellular apamin are shown in Table 2.

ISIs were measured for cells before and after external apamin (Fig. 5D) or in neurons dialyzed intracellularly with apamin (Fig. $5 E)$. When cells treated with apamin were stimulated at fast gamma, the peaks in the ISI distribution were less clearly separated than under control conditions. For both apamin-treated groups, $70 \mathrm{~Hz}$ stimulation generated one prominent peak near 15 $\mathrm{ms}$, with only residual ISIs corresponding to slow gamma output near $30 \mathrm{~ms}$. In response to $100 \mathrm{~Hz}$ stimulation, apamin appeared to shift the ISI distribution toward smaller values, although the peaks corresponding to slow gamma firing (20 ms ISI) were not abolished outright. Insets above ISI histograms in Figure $5 D$ show the cumulative distributions of ISIs generated in control (black lines) and bath-applied apamin (gray lines). The cumulative distributions at 70 and $100 \mathrm{~Hz}$ are significantly different from control in the presence of bath-applied apamin $(D=0.216$ and 0.307 , respectively; corresponding $p$-values $<0.0005$ for each comparison), whereas the distributions at $40 \mathrm{~Hz}$ do not differ significantly between control and bath-applied apamin $(D=$ $0.094, p=0.131)$. The apamin-associated shift at 70 and $100 \mathrm{~Hz}$ is toward smaller ISI values, corresponding to higher frequency firing than in control. Insets above ISI histograms in Figure $5 E$ show the cumulative distributions of ISIs for the two different apamin application methods: via the patch pipette (black dotted lines) overlaid on the cumulative distributions in the presence of bath-applied apamin from Figure $5 D$ (gray lines). There were no significant differences in distributions at the different gamma frequencies between the two apamin application methods $(D=$ $0.053, p=0.752 ; D=0.096, p=0.076 ; D=0.097, p=0.139$; for 40, 70, and $100 \mathrm{~Hz}$ stimulation, respectively), indicating that apamin's effect, shifting ISI distributions to smaller values, is a result of SK channel block in the postsynaptic cell.

Heat maps of pooled data for all neurons examined (Fig. $5 F-H)$ demonstrate that apamin, whether applied externally or 

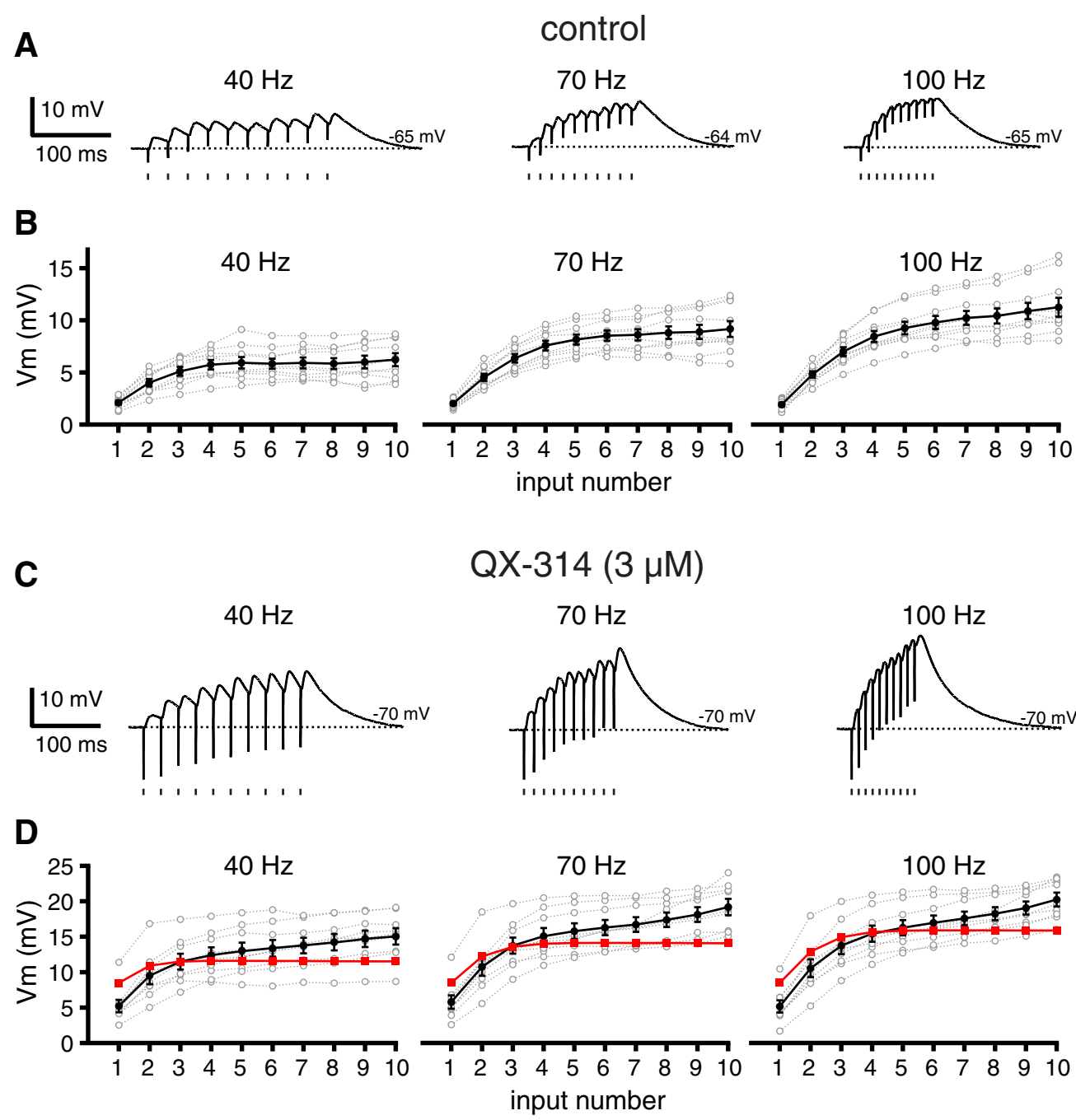

Figure 4. No evidence of synaptic depression during the train in response to gamma frequency stimulation at SCS. $A$, Example traces showing EPSPs in response to subthreshold trains of SC stimulation in control conditions. The amplitude of the voltage deflection increases across the train whether the input is at slow gamma (40 Hz) or fast gamma (70 Hz or $100 \mathrm{~Hz})$. $\boldsymbol{B}$, Plots of the membrane peak responses for $n=10$ neurons measured from baseline as a function of input number show a similar pattern of increasing voltage deflection across the stimulus train, in response to 40,70, or $100 \mathrm{~Hz}$ input. C, Example traces showing EPSPs in response to SC stimulation in the presence of QX-314 (3 $\mu \mathrm{M})$ in the recording electrode to block sodium spikes. D, Plots of the membrane responses as a function of input number for 40,70 , or $100 \mathrm{~Hz}$ input for $n=9$ neurons. The amplitude of the voltage deflection is larger than in $\boldsymbol{B}$ and the same pattern of increased summation over the train of 10 inputs is observed, indicating a lack of synaptic depression in response to gamma frequency stimulation. The red traces represent the model output when $\mathrm{Na}{ }^{+}$conductance was set to zero to simulate the effect of QX-314. In $\boldsymbol{B}$ and $\boldsymbol{D}$, filled black circles represent group-averaged data and open gray circles indicate data from individual cells.

intracellularly, was associated with a 1:1 input:output relationship across more of the range of gamma than control, suggesting that SK block relaxes the constraint on high-frequency firing rates, allowing cells to fire at higher gamma frequencies. These results suggest that SK channels on CA1 pyramidal neurons ordinarily restrict output to the slow gamma range in response to SC input, but that blocking these channels removes that constraint, extending the range of frequencies to which these cells can respond.

The apical dendrites of CA1 hippocampal neurons express high levels of A-type (Kv4.2) potassium channels in a gradient that increases with distance from the soma (Hoffman et al., 1997; Chen et al., 2006). $I_{\mathrm{A}}$ activates rapidly in response to even small depolarizations in membrane potential, dampening excitability in a highly localized manner (Hoffman et al., 1997; Frick et al., 2004), and could therefore contribute to the restriction on following high-frequency trains of SC inputs. We performed our stimulations in the presence of $100 \mu \mathrm{M} \mathrm{BaCl}_{2}$ to reduce $\mathrm{I}_{\mathrm{A}}$. At this concentration, $\mathrm{BaCl}_{2}$ has been shown to affect only $I_{\mathrm{A}}$ and inward rectifier $\mathrm{K}^{+}$channels (Gasparini et al., 2007). An example experiment is shown in Figure 6, $A$ and $B$. Stimulus intensities that generated 8.9 $\pm 0.2 \mathrm{APs}$ at $40 \mathrm{~Hz}$ in control and 8.4 $\pm 0.2 \mathrm{APs}$ in $100 \mu \mathrm{M} \mathrm{BaCl}_{2}\left(p=0.014, t_{(7)}=-3.275\right.$, paired samples $t$ test, $n=8$ ) led the cells to fire significantly less at 70 and $100 \mathrm{~Hz}$ in the presence of $\mathrm{BaCl}_{2}$ than in the control (at $70 \mathrm{~Hz}, 6.5 \pm 0.2$ decreased to $5.6 \pm 0.2$ in $\mathrm{BaCl}_{2} ; p=0.001, t_{(7)}=-5.240$; and at 100 $\mathrm{Hz}, 5.3 \pm 0.1$ control decreased to $4.5 \pm 0.1$ in $\mathrm{BaCl}_{2} ; p<0.0005$, $\left.t_{(7)}=-6.533\right)$, indicating that blocking $I_{\mathrm{A}}$ further restricted the output in response to fast gamma input. This was confirmed by plotting the ISIs from spike trains before and after $100 \mu \mathrm{M} \mathrm{BaCl}_{2}$ (Fig. 6C). In control conditions, as before, stimulation at $100 \mathrm{~Hz}$ or $70 \mathrm{~Hz}$ generated two peaks (Fig. $6 \mathrm{C}$, solid black bars). In $\mathrm{BaCl}_{2}$ (Fig. $6 C$, open gray bars), the ISIs corresponding to fast gamma firing were greatly diminished. Cumulative distributions of ISIs are shown above histograms (Fig. $6 C$, insets). Though very similar to control, the distribution in response to $40 \mathrm{~Hz}$ stimulation in $\mathrm{BaCl}_{2}$ is shifted to the left enough to give a significant difference in the distributions $(D=0.123, p=0.009)$, likely due to a 
A

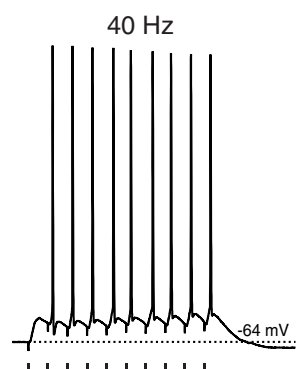

control

$70 \mathrm{~Hz}$

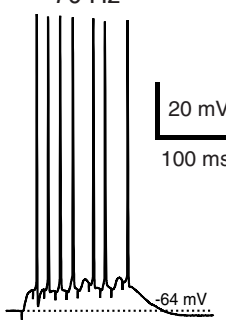

B

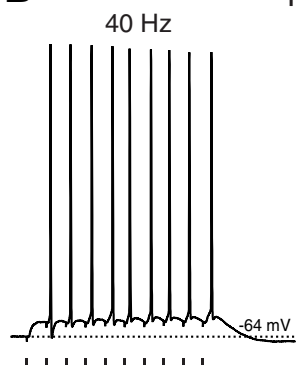

apamin (100 nM)

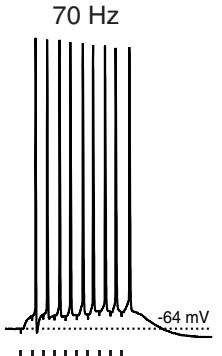

C intracellular apamin $(100 \mathrm{nM})$

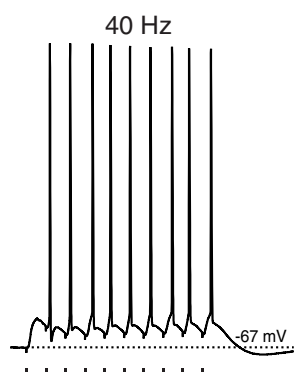

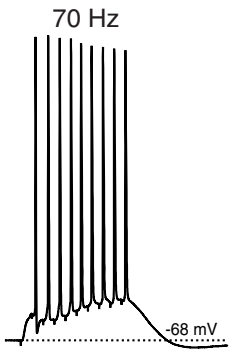

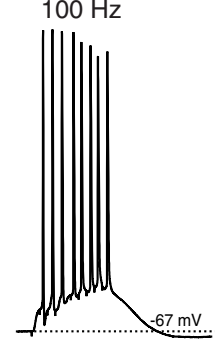

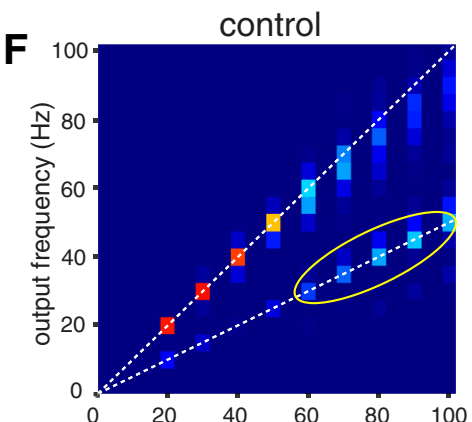

G

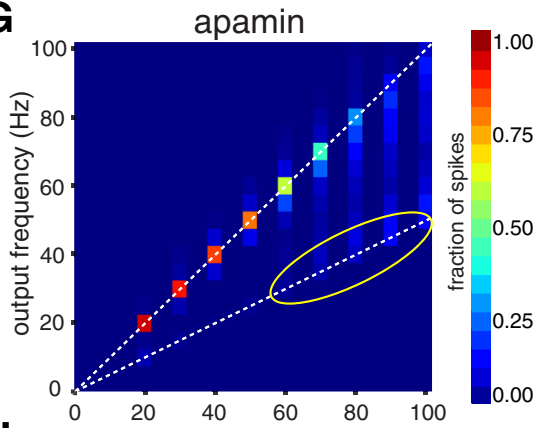

H
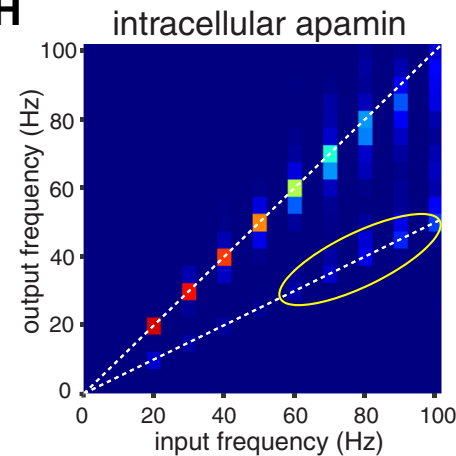

D

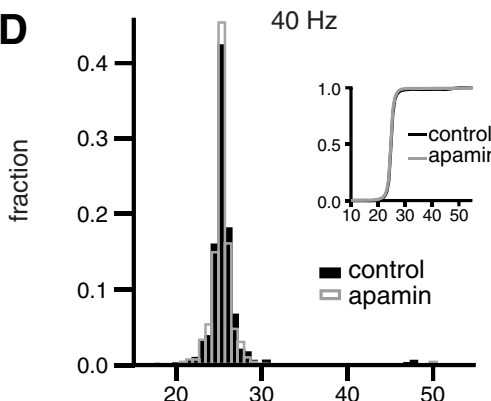

E

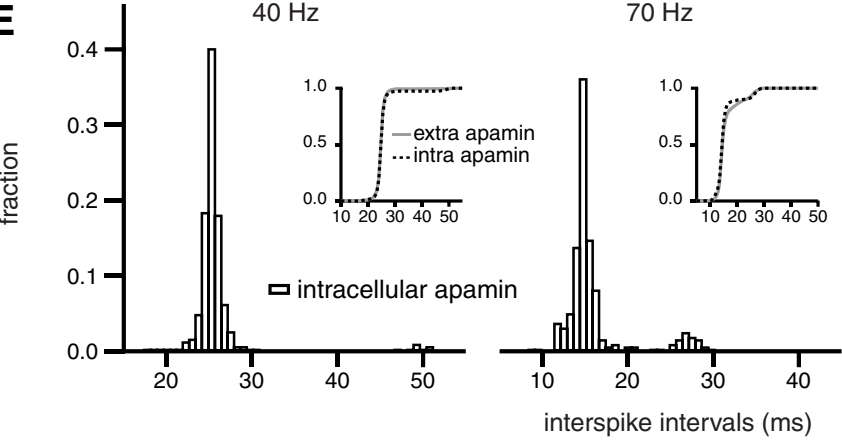

$70 \mathrm{~Hz}$
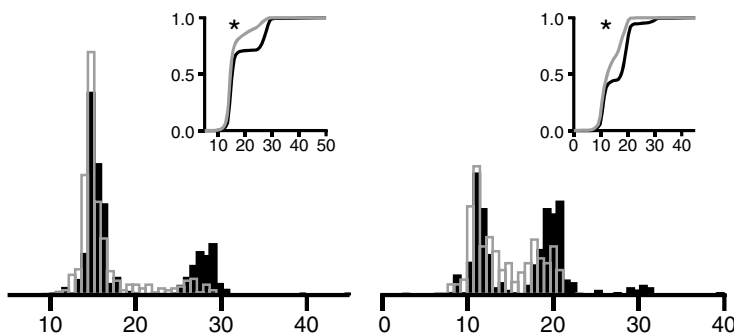

$100 \mathrm{~Hz}$

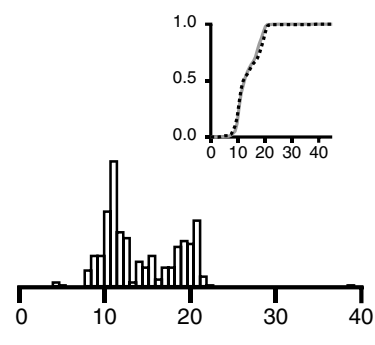

Figure 5. SK current block allows CA1 pyramidal neurons to fire at fast gamma in response to SC stimulation. $A$, Representative traces in response to 40,70 , or $100 \mathrm{~Hz} S \mathrm{C}$ stimulation in control ( $A$ ) and $100 \mathrm{~nm}$ apamin either externally applied (B) or applied intracellularly in the recording pipette ( $\boldsymbol{C}$. Stimulus inputs are indicated below voltage traces with tick marks. In the presence of apamin, external or internal, the cells more reliably follow 70 and $100 \mathrm{~Hz}$ stimulation than they do in control. D, ISI distributions for 40, 70, and $100 \mathrm{~Hz}$ SC stimulation in control (Figure legend continues.) 
Table 2. Selective precision of SC stimulation persists across pharmacological manipulations

\begin{tabular}{llll}
\hline $\begin{array}{l}\text { Stimulation } \\
\text { frequency }(\mathrm{Hz})\end{array}$ & Avalue $(95 \% \mathrm{Cl})$ & & \\
\cline { 2 - 4 } & Apamin & Carbachol & BAPTA \\
\hline 40 & $0.934(0.921-0.948)$ & $0.967(0.962-0.972)$ & $0.894(0.871-0.916)$ \\
70 & $0.757(0.722-0.793)$ & $0.843(0.815-0.870)$ & $0.658(0.619-0.696)$ \\
100 & $0.570(0.517-0.622)$ & $0.666(0.623-0.709)$ & $0.342(0.205-0.312)$ \\
\hline
\end{tabular}

Vector strength $r$ (with $95 \% \mathrm{Cl}$ ) for experiments with different drugs for trains of 10 stimuli applied at three different frequencies.

few slower ISIs in the control distribution, resulting in a gap between the two curves as the cumulative distribution approaches 1 . When the stimulation frequency was at 70 or $100 \mathrm{~Hz}$, $\mathrm{BaCl}_{2}$ shifted the ISIs to larger values $(D=0.319$ and $0.266, p<$ 0.0005 for each), corresponding to slow gamma firing. Heat maps of pooled data for all neurons show that the 2:1 input:output relationship that arises in control conditions around 50 to $60 \mathrm{~Hz}$ (Fig. 6D) has a sharper separation in $100 \mu \mathrm{M} \mathrm{BaCl}_{2}$ (Fig. 6E).

To determine whether the effect that we saw above was due to blockade of the inward rectifying potassium current, which is affected by lower concentrations of $\mathrm{BaCl}_{2}$ (Schram et al., 2003; Chatelain et al., 2005), rather than to the reduction of $I_{\mathrm{A}}$, we repeated these experiments in the presence of $20 \mu \mathrm{M} \mathrm{BaCl}_{2}$ (Gasparini, 2011). When the stimulation was such that $40 \mathrm{~Hz}$ input generated $8.9 \pm 0.2$ in control and $8.8 \pm 0.2$ in $20 \mu \mathrm{M} \mathrm{BaCl}_{2}(p=$ $0.344, z=-0.946$, Wilcoxon signed-rank test, $n=7)$, there was no difference between these two conditions at either $70 \mathrm{~Hz}(6.9 \pm$ 0.1 vs $6.9 \pm 0.2, p=0.917, z=-0.105)$ or $100 \mathrm{~Hz}(5.5 \pm 0.1$ vs $5.4 \pm 0.1, p=0.091, z=-1.690)$.

Our results suggest that reduction of $I_{\mathrm{A}}$ in this context tightens the restriction on the output of CA1 pyramidal neurons engaged by SC input. Therefore, the availability of $I_{\mathrm{A}}$, which has a voltagedependent component (Hoffman et al., 1997) as well as responsiveness to neuromodulators (Hoffman and Johnston, 1999), may be a means by which subtle adjustments are made to firing frequency in response to temporally precise SC input.

The effect of blocking $\mathrm{I}_{\mathrm{A}}$ is counterintuitive because the blockade of an outward current resulted on average in longer, not shorter, ISIs and therefore in a generalized decrease in excitability. In the presence of $100 \mu \mathrm{M} \mathrm{BaCl}_{2}$, the APs are markedly wider than in control (compare Fig. $6 A$ and $B$ ). Broadening the APs likely increases calcium influx and facilitates SK activation, ultimately producing a net increase rather than decrease in outward current during the ISI. This interaction among $I_{\mathrm{A}}$, calcium, and $I_{\mathrm{SK}}$ has been demonstrated in serotonergic neurons of the dorsal

\section{$\leftarrow$}

(Figure legend continued.) (solid black bars, $n=10$ ) and external apamin (open gray bars). In both conditions, $40 \mathrm{~Hz}$ stimulation generates a single ISI peak around $25 \mathrm{~ms}$, corresponding to $40 \mathrm{~Hz}$ firing. In the presence of apamin, the peak ISIs shift toward smaller values when stimulation is at 70 and $100 \mathrm{~Hz}$. Insets, Cumulative distributions of ISIs for control (black lines) and external apamin (gray lines) at the respective frequencies. $x$-axes, $|S|$; $y$-axes, cumulative fraction. Asterisks indicate significant differences in the cumulative distributions before and after externally applied apamin. $\boldsymbol{E}$, ISI distributions for 40,70 , and $100 \mathrm{~Hz}$ SC stimulation when apamin was applied intracellularly. Results are similar to the effect of bath-applied apamin in $\mathbf{D}$. Insets, Cumulative distributions of ISIs for intracellular apamin (black dotted lines, $n=8$ ), overlaid on the cumulative distributions for bath-applied apamin from $\boldsymbol{D}$ (gray lines). There are no significant differences in the distributions between the two apamin application methods. $\boldsymbol{F}-\boldsymbol{H}$, Heat map representations of input:output relationships for the pooled data of all the neurons control $(\boldsymbol{F})$, external apamin $(\boldsymbol{G})$, and intracellular apamin $(\boldsymbol{H})$. The 1:1 relationship in control cells gives way to 2:1 above $60 \mathrm{~Hz}$ (highlighted by the yellow ellipses), whereas in both apamin groups, it remains dominated by 1:1 at higher frequencies. raphe nucleus (Ishibashi et al., 2016). The next set of experiments was conducted to test this possibility.

\section{SK block occludes the effects of $I_{\mathrm{A}}$ block}

Given that SK and $I_{\mathrm{A}}$ have seemingly opposing effects on fast gamma firing in response to SC input, we investigated what interaction occurred if we blocked both simultaneously. We established our control baseline, verified the firing behavior in apamin, and continued with apamin plus $100 \mu \mathrm{M} \mathrm{BaCl}_{2}$, as shown in Figure 7, $A-C$. The example cell in Figure $7 A$ shows the usual pattern of firing in control at 40, 70, and $100 \mathrm{~Hz}$, followed by increased efficacy in firing at fast gamma in the presence of apamin (Fig. $7 B$ ). When we added $100 \mu \mathrm{M} \mathrm{BaCl}_{2}$ to the external solution, the cell still followed fast gamma frequency input as it had in apamin; in many cases, firing continued with a few APs after the end of the stimulus train (Fig. 7C), likely because the simultaneous blockade of $I_{\mathrm{SK}}$ and $I_{\mathrm{A}}$ removes two of the main hyperpolarizing currents that would ordinarily limit the duration of the summated EPSPs.

The Friedman test indicated that the number of APs fired in response to $40 \mathrm{~Hz}$ input was significantly different between treatment groups $\left(\chi_{(2)}^{2}=6.118, p=0.047\right)$, but post hoc analysis did not reflect this difference. For $n=8$ neurons, the cells fired $9.1 \pm$ 0.1 APs in control conditions, $9.3 \pm 0.2$ in apamin, and $9.3 \pm 0.2$ in apamin $/ 100 \mu \mathrm{M} \mathrm{BaCl}_{2}$ (control vs apamin, $p=0.634$; control vs apamin $/ \mathrm{BaCl}_{2}, p=0.240$; apamin vs apamin $/ \mathrm{BaCl}_{2}, p=$ $1.000)$. At $70 \mathrm{~Hz}$, the cells fired $7.7 \pm 0.1 \mathrm{APs}$ in control conditions, $8.4 \pm 0.3$ in apamin, and $9.1 \pm 0.2$ in apamin/100 $\mu \mathrm{M}$ $\mathrm{BaCl}_{2}$, with the Friedman test $\chi_{(2)}^{2}=10.129, p=0.006$. There was a trend toward more APs in apamin versus control that did not reach significance by post hoc analysis $(p=0.114)$. The difference between control and apamin/100 $\mu \mathrm{M} \mathrm{BaCl}_{2}$ is significant, however $(p=0.005)$. In response to $100 \mathrm{~Hz}$ input, cells fired $6.2 \pm 0.2$ APs in control conditions, $6.8 \pm 0.3$ in apamin, and $7.1 \pm 0.3$ in apamin $/ \mathrm{BaCl}_{2}$, which was significant by the Friedman test $\left(\chi_{(2)}^{2}=\right.$ 9.867, $p=0.007)$. Post hoc analysis gave significant increases over control for apamin and apamin $/ \mathrm{BaCl}_{2}(p=0.037$, and $p=0.018$, respectively). The distributions of ISIs for those spikes during the stimulus train are shown in Figure $7 D$ for the cells in apamin before and after $\mathrm{BaCl}_{2}$. The ISI distributions in apamin (solid gray bars) were similar to those shown in Figure 5. The addition of $100 \mu \mathrm{M} \mathrm{BaCl} 2$ on top of apamin (open black bars) did not noticeably shift the ISI distributions compared with apamin alone at 40 or $100 \mathrm{~Hz}$, but there was a leftward shift in the ISI distributions at $70 \mathrm{~Hz}$.

The insets in Figure $7 D$ show cumulative distributions of ISIs in apamin (gray lines) and with the addition of $100 \mu \mathrm{M} \mathrm{BaCl}$ (black dotted lines). When the stimulation was at 40 or $100 \mathrm{~Hz}$, the distributions are quite similar, with small maximum differences $(D=0.090, p=0.097$ and $D=0.068, p=0.168$ for 40 and $100 \mathrm{~Hz}$, respectively). However, in response to $70 \mathrm{~Hz}$ stimulation, the leftward shift in ISI distribution is evident (maximum difference $D=0.333, p<0.005$ ). These data suggest that blocking $I_{\mathrm{A}}$ when SK is already compromised does not reverse the effect of apamin, possibly because one effect of $I_{\mathrm{A}}$ is to increase the $\mathrm{Ca}^{2+}$-activation of the SK channel. However, the removal of both hyperpolarizing potassium currents may have an additive generalized effect on excitability.

\section{BAPTA has an effect similar to apamin}

We further explored the role of intracellular $\mathrm{Ca}^{2+}$ in frequency selectivity by using the fast $\mathrm{Ca}^{2+}$ chelator BAPTA in the patch pipette. The acid and the tetrapotassium forms of BAPTA gave 
A

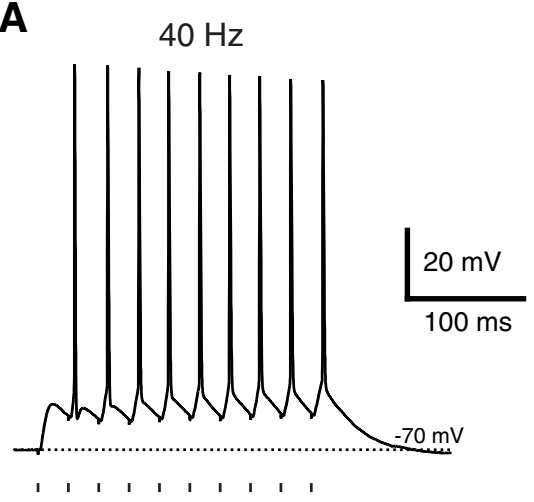

B
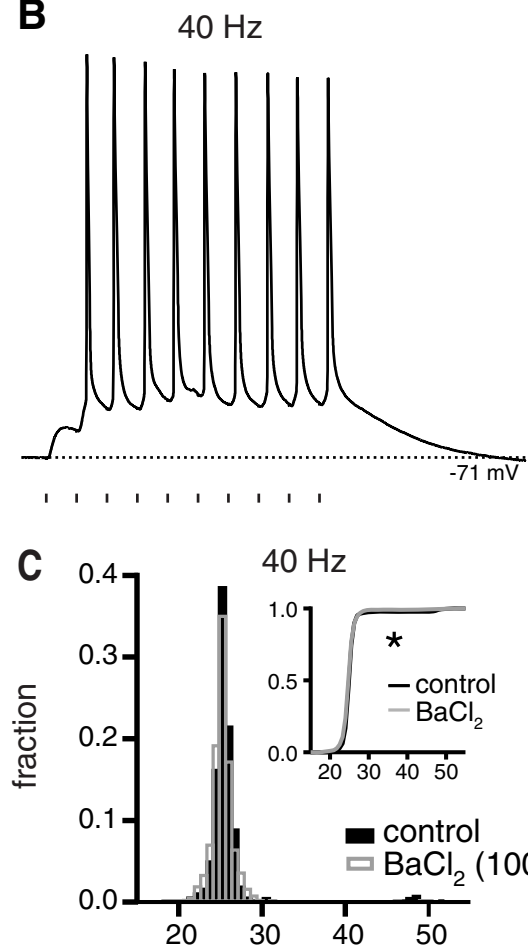

control

$70 \mathrm{~Hz}$

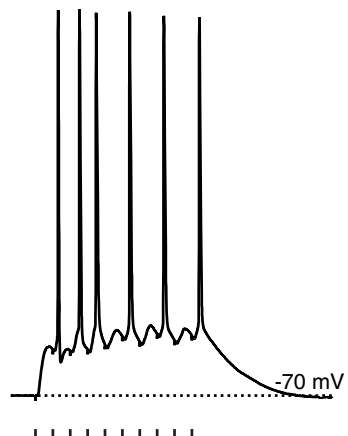

$\mathrm{BaCl}_{2}(100 \mu \mathrm{M})$
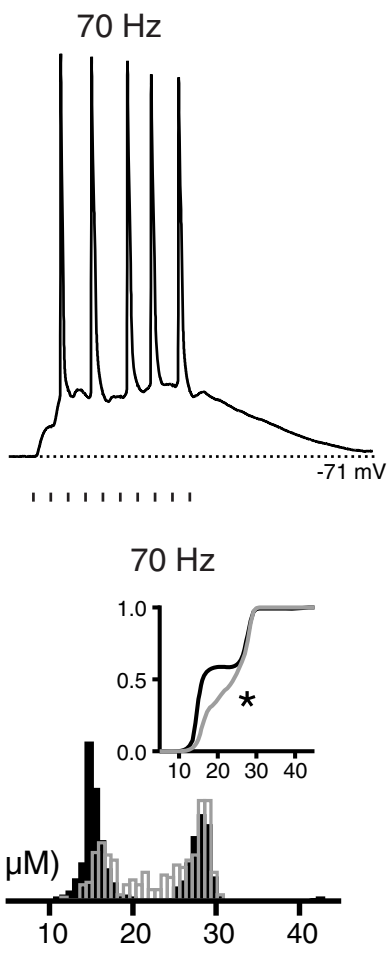

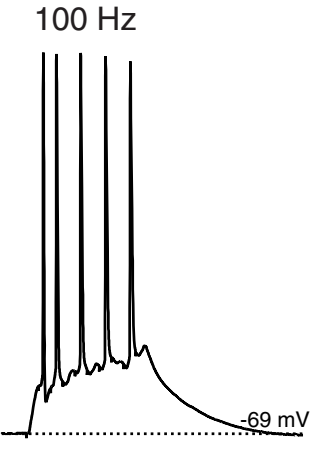

リーוイוー

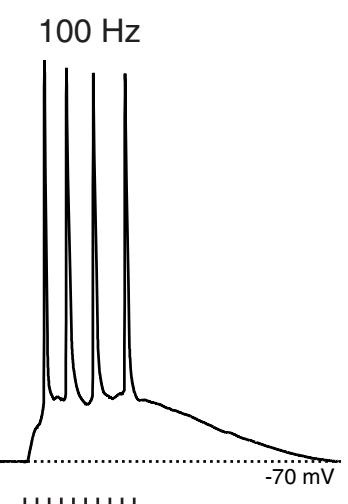

interspike intervals (ms)

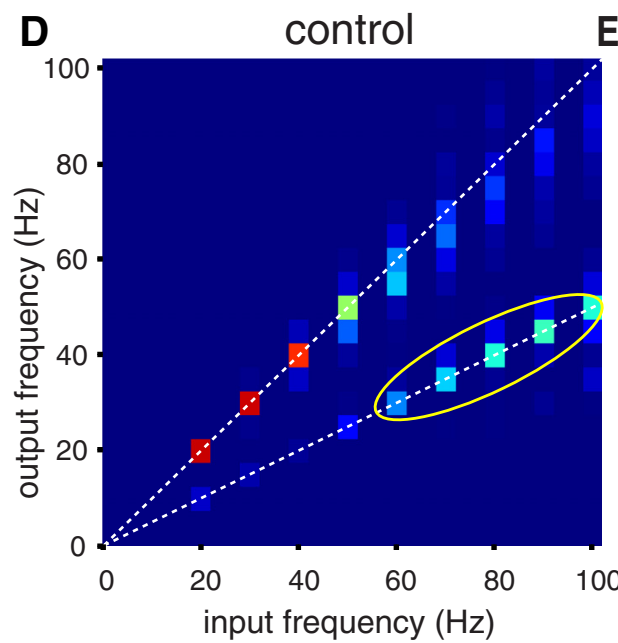

E 100

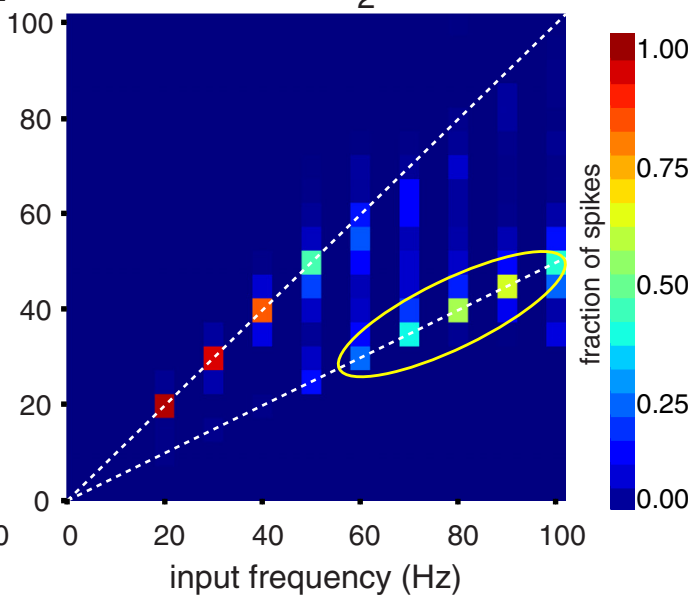

Figure 6. Reduction of $I_{A}$ enhances slow gamma firing in response to SC stimulation. $A, B$, Representative traces in response to 40,70, or $100 \mathrm{~Hz} S \mathrm{~S}$ stimulation in control $(\boldsymbol{A})$, or $100 \mu \mathrm{M} B a \mathrm{Cl}_{2}$ to block $I_{A}(B)$. The tendency to "skip" at fast gamma stimulation is more pronounced in the presence of $\mathrm{BaCl}_{2}(100 \mu \mathrm{M})$. $\mathrm{C}$, ISI distributions for 40, 70, and 100 Hz (Figure legend continues.) 
A

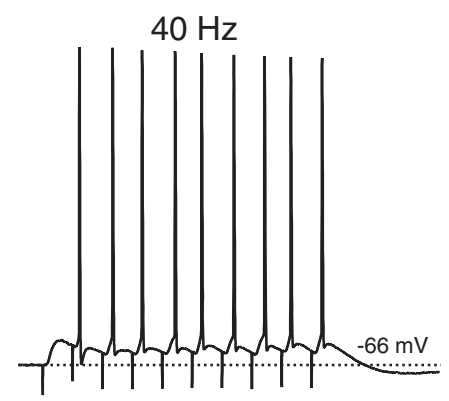

B $\quad 40 \mathrm{~Hz}$

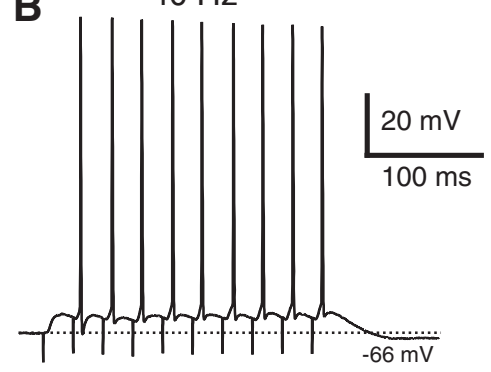

control

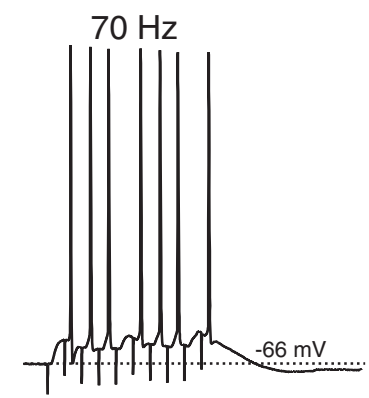

apamin $(2 \mu \mathrm{M})$

$70 \mathrm{~Hz}$

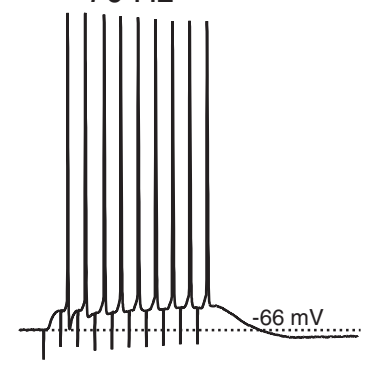

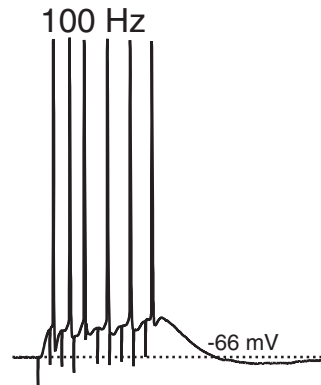

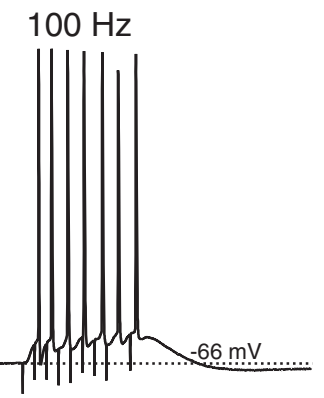

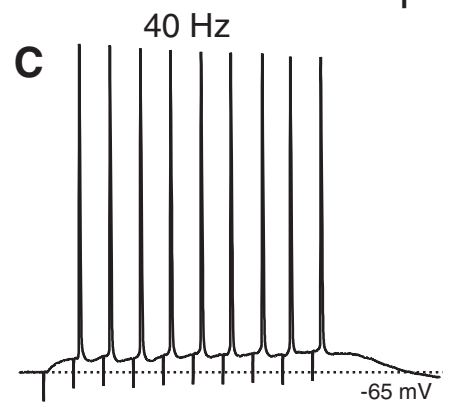

apamin $(2 \mu \mathrm{M}) \mathrm{BaCl}_{2}(100 \mu \mathrm{M})$
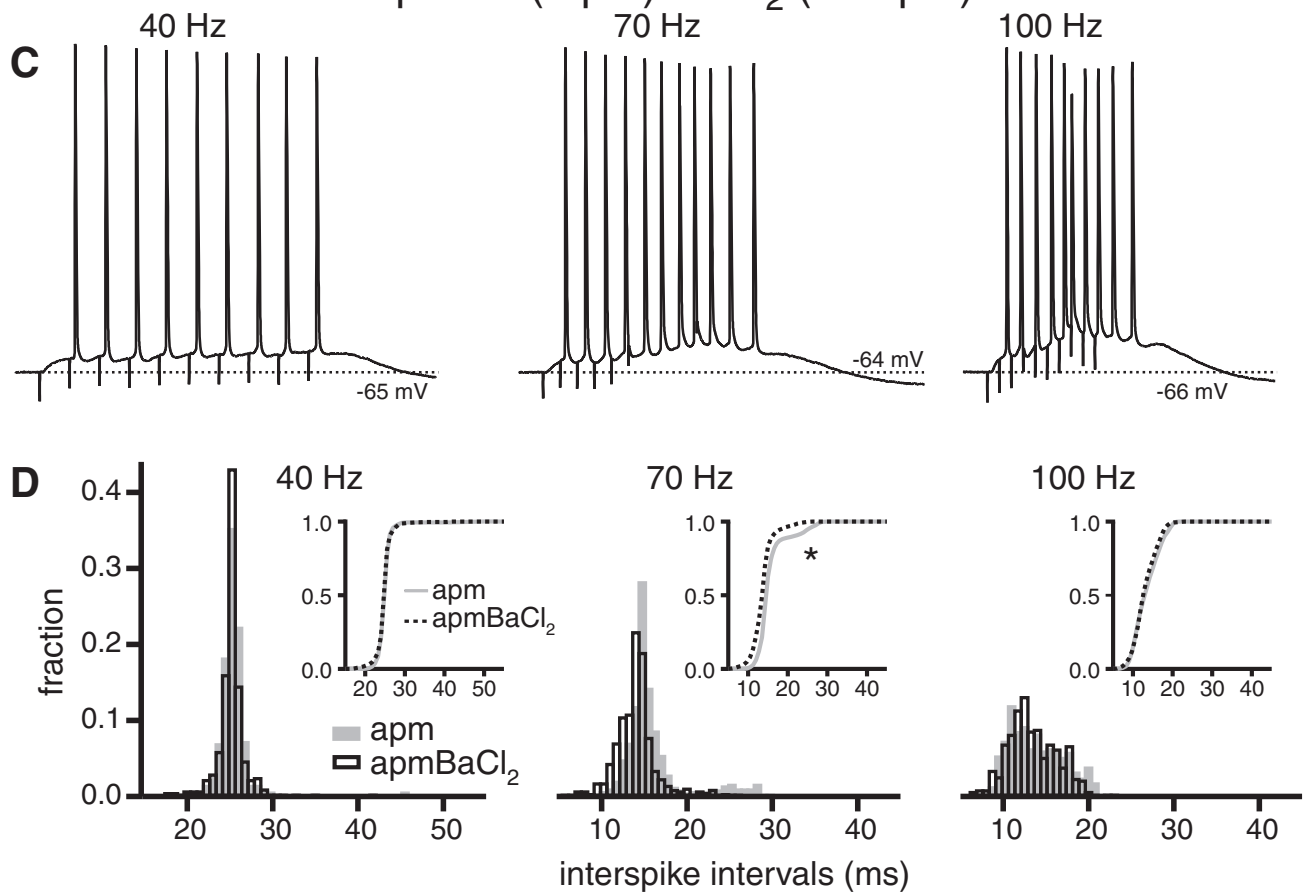

Figure 7. SK block has a dominant influence over $I_{A}$ block. $\boldsymbol{A}-\boldsymbol{C}$, Representative traces in response to 40,70 , or $100 \mathrm{~Hz}$ input in control $(\boldsymbol{A})$, apamin $(\boldsymbol{B})$, and apamin with $100 \mu \mathrm{m} \mathrm{BaCl}$, added $(\boldsymbol{C})$. $\boldsymbol{D}, \mid \mathrm{SI}$ distributions for the three frequencies tested in apamin (solid gray bars, $n=8$ ) and apamin/ $/ \mathrm{BaCl}_{2}$ (open blackbars). The addition of $100 \mu \mathrm{mBaCl}$ on top of apamin does not prevent firing at fast gamma nor shift the ISIs back toward control distributions, suggesting that the overriding factor under these conditions is the block of SK channels. In fact, at $70 \mathrm{~Hz}$, the combined block of $\mathrm{I}_{\mathrm{A}}$ and $\mathrm{SK}$ is associated with a shift toward smaller ISIs farther from control distributions and in the opposite direction of I $_{\mathrm{A}}$ block alone. Insets, Cumulative distributions of ISIs for apamin (gray lines) and apamin $+100 \mu \mathrm{m} \mathrm{BaCl} \mathrm{I}_{2}$ (dotted lines). $x$-axes, ISI; $y$-axes, cumulative fraction. Asterisk in $70 \mathrm{~Hz}$ panel indicates a significant leftward shift in the cumulative distribution upon addition of $100 \mu \mathrm{m} \mathrm{BaCl} 2$ on top of apamin.

(Figure legend continued.) in control (solid black bars) and $\mathrm{BaCl}_{2}$ (open gray bars). Insets, Cumulative distributions of ISIs for control (black lines) and $\mathrm{BaCl}_{2}$ (gray lines) at the respective frequencies. $x$-axes, ISI; $y$-axes, cumulative fraction. Asterisks indicate significant differences in the cumulative distributions before and after $\mathrm{BaCl}_{2} . \boldsymbol{D}, \boldsymbol{E}$, Heat map representations of input: output relationships for control $(\boldsymbol{D})$ and $100 \mu \mathrm{MBaCl}(\boldsymbol{E})$ from the pooled data of all the neurons examined $(n=8)$. When $I_{A}$ is reduced with $\mathrm{BaCl}_{2}$, there is no 1:1 firing beyond input frequencies $>60 \mathrm{~Hz}$, but rather 2:1 firing, as highlighted by the yellow ellipses. similar results in terms of number of APs evoked; therefore, the results were grouped together. We found that BAPTA relaxes the frequency selectivity in a manner similar to apamin. When cells dialyzed with BAPTA fired $9.0 \pm 0.03$ at $40 \mathrm{~Hz}$, they fired an average of $8.4 \pm 0.2$ at $70 \mathrm{~Hz}$ and $6.9 \pm 0.3$ at 100 $\mathrm{Hz}$. Using the Mann-Whitney $U$ test to evaluate differences between independent samples, we compared these results to the firing behavior of cells superfused with apamin (Fig. 5) and 
A

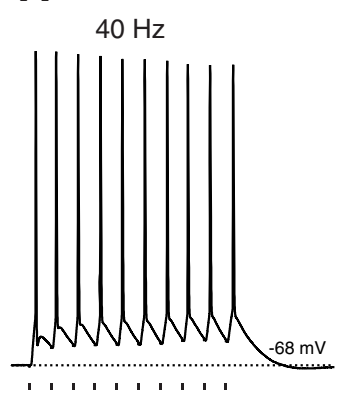

B

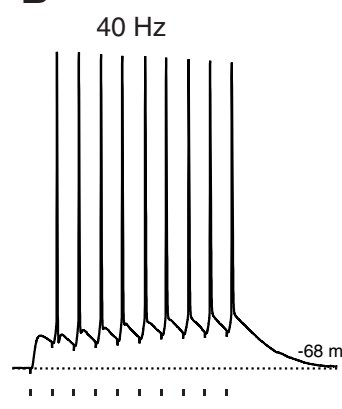

control

$70 \mathrm{~Hz}$

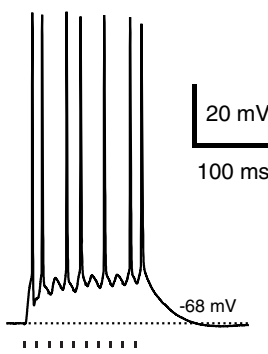

CCh $(2 \mu \mathrm{M})$

$70 \mathrm{~Hz}$

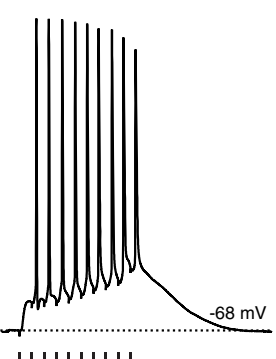

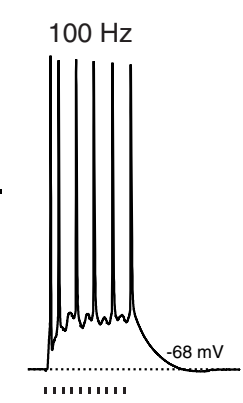

1, $1+\cdots \cdots+1$
C
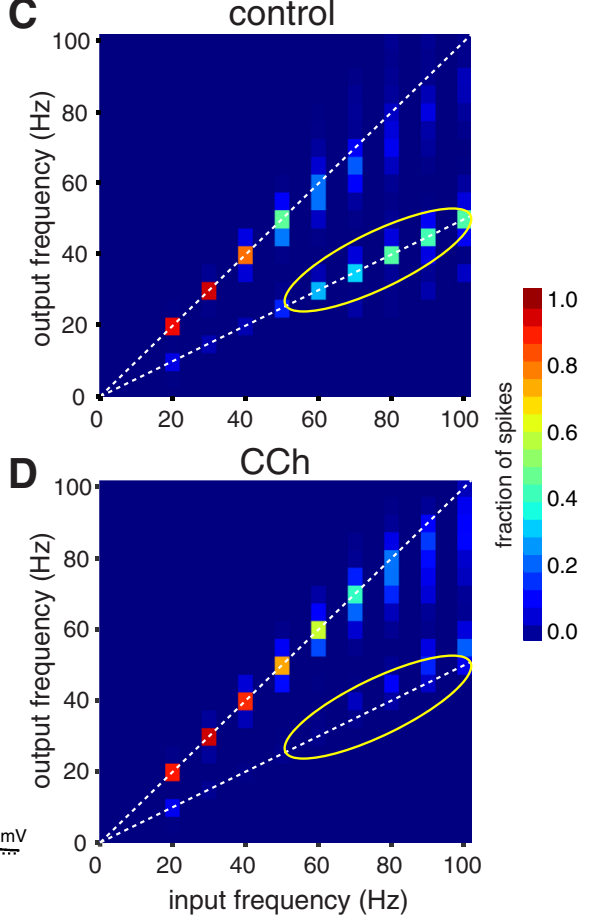

input frequency $(\mathrm{Hz}$

E

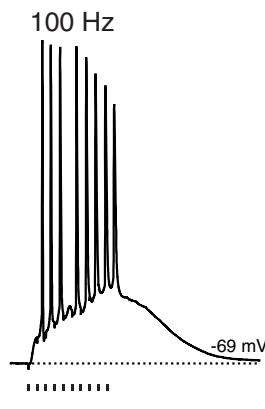

$100 \mathrm{~Hz}$
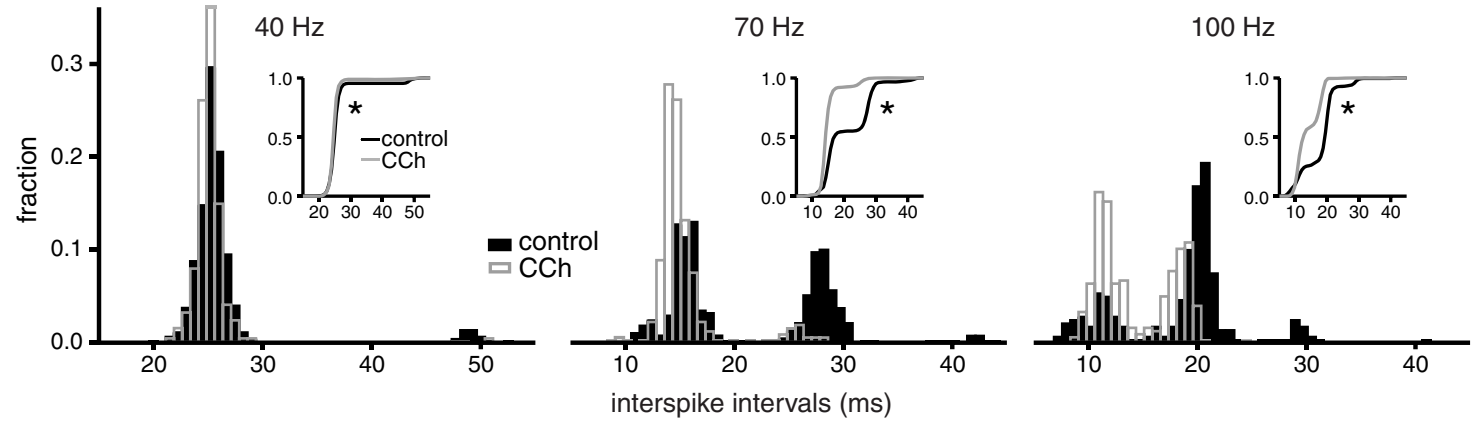

Figure 8. Acetylcholine receptor activation turns off the frequency selectivity for SC input. $\boldsymbol{A}, \boldsymbol{B}$, Representative traces at 40,70 , and $100 \mathrm{~Hz}$ in control conditions $(\boldsymbol{A})$ and after the addition of $2 \mu \mathrm{m}$ carbachol $(C \mathrm{Ch} ; \boldsymbol{B})$ to activate $\mathrm{ACh}$ receptors. In control, the cell skips several inputs at $70 \mathrm{~Hz}$ stimulation and every other input at $100 \mathrm{~Hz} \mathrm{stimulation,} \mathrm{but} \mathrm{after} \mathrm{the} \mathrm{addition} \mathrm{of} \mathrm{carbachol,} \mathrm{the} \mathrm{cell} \mathrm{is} \mathrm{able}$ to accurately follow the 70 and $100 \mathrm{~Hz}$ stimulus trains. $C, \boldsymbol{D}$, Heat map representations of the input:output relationship as measured in control $(\boldsymbol{C})$ and $(C \mathrm{Ch}(\boldsymbol{D})$ from the pooled data of all the neurons examined $(n=7)$. The yellow ellipses highlight the region of 2: 1 input:output relationship for fast gamma input frequencies. $E$, ISI distributions at 40, 70 , and 100 Hz in control (solid black bars) and after the addition of $2 \mu \mathrm{m}$ CCh (open gray bars). Insets, Cumulative distributions of ISIs for control (black lines) and CCh (gray lines) at the respective frequencies. $x$-axes, ISI; $y$-axes, cumulative fraction. Asterisks indicate significant differences in the cumulative distributions before and after $\mathrm{CCh}$.

found no significant differences in the number of APs fired $(p=0.720, U=49.5 ; p=0.211, U=61.0 ; p=0.661, U=$ 51.0, BAPTA vs apamin at 40, 70, and $100 \mathrm{~Hz}$, respectively, using an exact sampling distribution for $U$ ), suggesting that cells are better able to follow fast gamma input when intracellular calcium is chelated. Because BAPTA decreases the amplitude of the $\mathrm{Ca}^{2+}$ transient, it likely exerts its effects at least partially via a decrease in the activation of SK channels. Like apamin, BAPTA did not reverse the increased precision at lower frequency stimulation (Table 2).

\section{Cholinergic activity relaxes the frequency selectivity to SC input}

We next investigated how frequency selectivity might be modified in a physiologically relevant manner. Neuromodulators such as acetylcholine are thought to promote activity in a circuitspecific manner, transiently linking cell assemblies according to behavioral demands (Hasselmo, 2006; Marder, 2012). Using the broad-spectrum cholinergic agonist carbachol, we investigated the effects of cholinergic activation on the frequency preference at $\mathrm{SC}$ inputs to CA1. Figure 8 shows example traces in response to different gamma frequency stimulation before (Fig. $8 A$ ) and after (Fig. $8 B$ ) bath application of $2 \mu \mathrm{M}$ carbachol. According to the sign test, cells in control and carbachol fired similar numbers of APs at $40 \mathrm{~Hz}(9.0 \pm 0.1$ and $8.8 \pm 0.2$, respectively; exact $p=$ $0.219, n=7)$. At $70 \mathrm{~Hz}$, cells fired significantly more APs in carbachol $(8.2 \pm 0.2)$ than control $(6.3 \pm 0.2$; exact $p=0.016)$. This was true at $100 \mathrm{~Hz}$ as well (control, $5.3 \pm 0.1$; carbachol $6.4 \pm 0.2$; exact $p=0.016$ ). Like apamin and BAPTA, carbachol did not reverse the increased precision at lower frequency stimulation (Table 2).

When we measured the ISIs and plotted their distribution, we found that, as before, in control conditions, the ISI distribution for $100 \mathrm{~Hz}$ stimulation was dominated by intervals around $20 \mathrm{~ms}$ with a smaller peak near $10 \mathrm{~ms}$ (Fig. $8 E$, solid black bars). This relationship was reversed by carbachol (Fig. 8E, open gray bars), where the majority of ISIs now correspond to fast gamma firing. Shown above the histograms for carbachol are the cumulative 
distribution plots of ISIs in control (black lines) and with carbachol (gray lines). When the stimulation was at $40 \mathrm{~Hz}$, the distributions appear quite similar, although the maximum difference $D=0.166$ is significant $(p<0.0005)$, likely due to a small cluster of ISIs near $50 \mathrm{~ms}$ in control. In response to 70 and $100 \mathrm{~Hz}$ stimulation, the distinction is much more obvious, with carbachol shifting the ISIs toward smaller values with significant differences $(D=0.497$ and 0.530 , respectively; corresponding $p$-values $<0.0005)$. When we constructed heat maps of pooled data for all neurons for the two conditions, we saw that, in the presence of carbachol, cells more closely matched the 1:1 input: output relationship indicated by the white dotted line (Fig. $8 D$ ) than did control cells (Fig. 8C). Interestingly, we observed a resemblance between the above results and those that we collected in the presence of apamin to block SK channels (compare Figs. 5 and 8). Cholinergic activation affects multiple potassium conductances, including that of SK channels (Buchanan et al., 2010; Giessel and Sabatini, 2010). Acetylcholine, acting at muscarinic receptors and decreasing SK current, could ease the restriction on the frequency that CA1 pyramidal neurons are able to follow, allowing CA1 output to match fast gamma in response to fast gamma stimulation of SCs. To establish whether muscarinic or nicotinic receptors were responsible for the cholinergic modulation, we used a broad-spectrum muscarinic agonist, oxo-M $(0.2$ $\mu \mathrm{M})$. We found that oxo-M had an effect very similar to that of carbachol. As attested by the Wilcoxon signed-rank test for $n=9$ neurons, cells in control and oxo-M fired similar numbers of APs at $40 \mathrm{~Hz}(8.9 \pm 0.02$ and $9.0 \pm 0.1$, respectively; $p=0.917, z=$ $0.105)$. At $70 \mathrm{~Hz}$, cells fired significantly more APs in oxo-M $(8.5 \pm 0.2)$ than control $(7.3 \pm 0.2 ; p=0.008, z=2.666)$. This was true at $100 \mathrm{~Hz}$ as well (control, $5.80 \pm 0.11$; oxo-M, $7.2 \pm 0.3$; $p=0.008,2.666$ ). In addition, the number of spikes in the presence of oxo-M was not significantly different from that in the presence of the broad-spectrum agonist carbachol $(p=0.408$, $U=40.0$ for $40 \mathrm{~Hz} ; p=0.299, U=41.5$ for $70 \mathrm{~Hz} ; p=0.114, U=$ 47.0 for $100 \mathrm{~Hz}$, Mann-Whitney $U$ test using an exact sampling distribution for $U$ ). For these reasons, we conclude that cholinergic modulation of frequency selectivity in our experiments occurs through muscarinic receptors.

To test the hypothesis that cholinergic signaling influences firing frequency by decreasing SK channel activity, we performed occlusion experiments by analyzing the effect of carbachol $(2 \mu \mathrm{M})$ when perfused on neurons dialyzed with an intracellular solution containing apamin $(100 \mathrm{~nm})$. We found that the number of APs at each of the examined frequencies was not significantly different in the two conditions. For $n=8$, the paired $t$ test indicated that cells fired similar numbers of APs at $40 \mathrm{~Hz}(9.1 \pm 0.1$ in control (intracellular apamin) and $8.9 \pm 0.1$ upon perfusion of carbachol; $\left.t_{(7)}=-1.867, p=0.104\right), 70 \mathrm{~Hz}(8.4 \pm 0.2$ and $8.7 \pm$ 0.3 in control and in the presence of apamin, respectively; $t_{(7)}=$ $1.399, p=0.205)$ and $100 \mathrm{~Hz}(6.9 \pm 0.3$ and $7.4 \pm 0.3$ in control and in the presence of apamin, respectively; $t_{(7)}=1.818, p=$ 0.112). Although we cannot exclude other effects of carbachol, for example, through the nonspecific cation current $I_{\text {CAN }}$ (Knauer et al., 2013; Lin et al., 2017), we conclude that the relaxation of frequency selectivity by cholinergic modulation occurs mostly through the modulation of SK channels. Fluctuations in acetylcholine levels may therefore serve as a means by which multiple potassium conductances could be orchestrated, allowing CA1 to switch between slow or fast gamma firing as needed in response to SC input.

\section{Discussion}

We investigated the response of CA1 pyramidal neurons to trains of input from CA3 at different gamma frequencies. Our modeling and experimental results show the following: (1) in response to temporally precise $\mathrm{SC}$ input, intrinsic properties of CA1 pyramidal neurons limit their firing frequency to slow gamma and the evoked spikes lock more precisely to inputs in the slow versus fast gamma range; (2) this selectivity is due, at least in part, to activation of SK channels and is enhanced by $I_{\mathrm{A}}$ inactivation; and (3) the selectivity can be turned off by cholinergic modulation, allowing CA1 neurons to fire at fast gamma frequencies in response to fast gamma stimulation. These results suggest that the frequency selectivity is mediated by potassium conductances and subject to neuromodulation. However, the more precise firing at slower frequencies persisted throughout all pharmacological manipulations presented in this study; the mechanism for this more precise locking is unknown and requires further investigation.

\section{Role of SK}

In adult rats, SK channels are expressed in the soma and apical dendrites (Chen et al., 2014) in a nonuniform distribution that increases in the apical dendrite with distance from the soma (Ballesteros-Merino et al., 2012). $\mathrm{Ca}^{2+}$ that activates SK channels in pyramidal neurons may enter via NMDARs and R-type voltage-gated $\mathrm{Ca}^{2+}$ channels (VGCCs) in the dendrites (NgoAnh et al., 2005; Bloodgood and Sabatini, 2007; Wang et al., 2014) and via multiple types of VGCCs in the soma (Jones and Stuart, 2013). In the model, $\left[\mathrm{Ca}^{2+}\right]_{\mathrm{i}}$ in a thin shell beneath the cell membrane had contributions from all VGCCs, some of which were preferentially located on the dendrites, and activated SK channels, which were also preferentially located on the dendrites. Dendritic $\mathrm{Ca}^{2+}$ entry during synaptic stimulation provides a negative feedback mechanism that impaired the ability of the model neuron to follow $100 \mathrm{~Hz}$ trains of stimulation in the proximal dendrites, but not trains applied at the soma. The model provides an explanation for the apparently weaker effect of SK channels during somatic versus synaptic stimulation in our experiments.

\section{Role of $I_{A}$}

In our experiments, under control conditions, the frequency selectivity was engaged after the first two spikes at $100 \mathrm{~Hz}$; in contrast, blocking $I_{\mathrm{A}}$ allowed the frequency restriction to manifest immediately (compare Fig. 6A,B). The putative mechanism is that $I_{\mathrm{A}}$ limits the width of the AP, which also limits $\mathrm{Ca}^{2+}$ influx and SK channel activation; therefore, blocking $I_{\mathrm{A}}$ increases $\mathrm{Ca}^{2+}$ influx and SK channel activation. $I_{\mathrm{A}}$ inactivation is responsible for progressive AP broadening during high-frequency spike trains in CA1 pyramidal neurons (Kim et al., 2005). In vivo, $I_{\mathrm{A}}$ block may not be necessary to engage the frequency restriction because $I_{\mathrm{A}}$ in these neurons inactivates at depolarized membrane potentials (Hoffman et al., 1997). Therefore, the depolarizing ramp of synaptic input observed in these cells as a rodent moves through the place field of a CA1 neuron (Harvey et al., 2009; Bittner et al., 2017) could inactivate $I_{\mathrm{A}}$ and promote slow gamma firing and CA3-CA1 synchrony at slow gamma (Colgin et al., 2009) by tightening the restriction on following fast frequency input trains from CA3.

\section{Cholinergic modulation}

Cholinergic signaling at muscarinic receptors reduces SK current (Buchanan et al., 2010; Giessel and Sabatini, 2010). We found that carbachol and apamin both relax the limit on firing frequency, suggesting a possible link among cholinergic activity, 
diminished SK current, and possibly a more permissive environment for CA1's participation in fast gamma activity with CA3. In CA1 pyramidal neurons, carbachol also suppresses $I_{\mathrm{A}}$ (Hoffman and Johnston, 1998, 1999). Figure 7 suggests that the effect of $I_{\mathrm{A}}$ block is due to increased calcium influx and subsequent activation of SK channels and is likely masked in the presence of acetylcholine receptor activation, which has been shown to reduce SK sensitivity to calcium (Giessel and Sabatini, 2010). Increased levels of acetylcholine in the hippocampal formation are associated with successful encoding, whereas disruption of the cholinergic system impairs encoding (Barry et al., 2012). The cellular effects of acetylcholine on CA1 pyramidal neurons may facilitate encoding by decreasing selectivity for slow gamma frequency. Moreover, in the hippocampus and other parts of the CNS, SK channels are also modulated by adrenergic (Stocker et al., 1999; Faber et al., 2008; Maingret et al., 2008), dopaminergic (Han et al., 2007), and serotonergic (Andrade and Chaput, 1991; Perrier et al., 2013) signaling pathways, which may also affect frequency selectivity.

\section{Acetylcholine and novelty}

Microdialysis studies show that levels of acetylcholine in the hippocampus increase in novel environments (Acquas et al., 1996), whereas cholinergic lesions in rats diminish their exploration of novel objects (Winters and Bussey, 2005) and impair novel associations of locations and context (Easton et al., 2011). During exploration of familiar environments, slow gamma synchronization arises between CA1 and CA3 and fast gamma occurs in CA3 without necessarily entraining CA1 (Colgin et al., 2009). However, during exploration of a novel object in a previously empty location, fast gamma in CA3 entrained CA1 (Zheng et al., 2016a, but see Kemere et al. (2013) for differing results concerning novelty and CA3-CA1 coherence). Zheng et al. (2016a) suggest that the increase in fast gamma synchrony between $\mathrm{CA} 1$ and $\mathrm{CA} 3$ may be related to increased cholinergic activity associated with novelty. It has been suggested that higher cholinergic tone makes CA1 more excitable (Yamada-Hanff and Bean, 2013), which may promote fast gamma synchrony. Our observation that cholinergic agonists enable CA1 pyramidal neurons to follow trains of stimuli in the range of fast gamma could be among the mechanisms engaged by novelty to promote fast gamma synchrony and thereby efficient encoding.

\section{Selective attention to slow versus fast gamma in CA1} proximal dendrites

In this study, we propose two ways that area CA1 could selectively "listen" for slow gamma from CA3. The first way is by limiting the output frequency of CA1 neurons in response to SC input due to properties specific to their proximal dendrites. This limitation is relevant because, in vivo, some neurons fire on multiple (two to four) gamma cycles within a theta cycle (see Fig. 3 in Zheng et al., 2016b). Our data show that CA1 neurons tend to fire at slow gamma even when they receive fast gamma input frequencies, which might contribute to the high ratio of CA3 to CA1 slow gamma power compared with the ratio of CA3 to CA1 fast gamma power (See Fig. 2 B in Colgin et al., 2009). For increased synaptic stimulation intensities, the selectivity was somewhat attenuated because CA1 neurons fired more APs in response to fast gamma input than at baseline; however, significant differences in the numbers of APs due to input frequency were still observed (Table 1). Second, we show that the phase locking of individual neurons to input trains in the slow gamma regime is significantly tighter than to those in the fast gamma regime, partially accounting for the greater proportion of CA1 neurons that lock to slow gamma in CA3 compared with fast gamma in CA3 (53\% vs 33\%, respectively; Colgin et al., 2009). However, none of our pharmacological manipulations reversed or abolished the tighter locking to slow frequencies, so the underlying mechanism and its possible modulation are unknown.

Our approach postulates that a subset of CA3 neurons provides highly synchronized packets of input during gamma in CA3, so we measured the response to pulsatile trains of input. However, the gamma oscillations in the local field potential observed in CA1 could also contribute to phase locking at gamma frequencies via complementary mechanisms. To investigate this possibility, Broicher et al. (2012) applied noisy sinusoidal stimuli to the soma using the dynamic clamp in vitro under simulated high and low conductance states with a mean bias current that resulted in a background firing rate of either 2 or $8 \mathrm{~Hz}$. The tightest phase locking occurred in the theta band, except that a plateau in vector strength was observed between 8 and $100 \mathrm{~Hz}$ for higher firing rates in the high conductance state. Therefore, their study found no selectivity within the gamma band; however, we show here that input at the soma does not engage dendritic selectivity mechanisms.

Another study directly investigated dendritic mechanisms by which the envelope of high-frequency synchronous inputs in the LFP could preferentially phase lock somatic APs despite the lowpass filtering properties of the dendrite. Kalmbach et al. (2017) injected white noise into the dendrites of cortical pyramidal neurons and reverse engineered the dendritic filter that could produce the observed dendritic membrane potential as the output with the injected white noise as the input. This filter had a nonlinear component with a preferred stimulus rise time of $\sim 4 \mathrm{~ms}$. For a sinusoidal oscillation in the LFP, a 4 ms rise time accompanied by at least a $4 \mathrm{~ms}$ fall time would equate to a preferred frequency of $125 \mathrm{~Hz}$, somewhat above the fast gamma frequency range. This nonlinear dendritic filter is a third approach to selective receptivity to slow versus fast gamma that may complement our two approaches described above if nonlinear filters selective for these bands are instantiated in the dendrites of CA1 neurons.

In summary, our results suggest that the intrinsic properties of the proximal dendrites of CA1 pyramidal neurons may play an essential role in the recruitment of these neurons into gamma phase locking and coherence with the upstream CA3 region under different behavioral conditions.

\section{References}

Acquas E, Wilson C, Fibiger HC (1996) Conditioned and unconditioned stimuli increase frontal cortical and hippocampal acetylcholine release: effects of novelty, habituation, and fear. J Neurosci 16:3089-3096. CrossRef Medline

Aloisi AM, Casamenti F, Scali C, Pepeu G, Carli G (1997) Effects of novelty, pain and stress on hippocampal extracellular acetylcholine levels in male rats. Brain Res 748:219-226. CrossRef Medline

Andrade R, Chaput Y (1991) 5-Hydroxytryptamine4-like receptors mediate the slow excitatory response to serotonin in the rat hippocampus. J Pharmacol Exp Ther 257:930-937. Medline

Atherton LA, Dupret D, Mellor JR (2015) Memory trace replay: the shaping of memory consolidation by neuromodulation. Trends Neurosci 38:560570. CrossRef Medline

Ballesteros-Merino C, Lin M, Wu WW, Ferrandiz-Huertas C, Cabañero MJ, Watanabe M, Fukazawa Y, Shigemoto R, Maylie J, Adelman JP, Luján R (2012) Developmental profile of SK2 channel expression and function in CA1 neurons. Hippocampus 22:1467-1480. CrossRef Medline

Barry C, Heys JG, Hasselmo ME (2012) Possible role of acetylcholine in regulating spatial novelty effects on theta rhythm and grid cells. Front Neural Circuits 6:5. CrossRef Medline

Bianchi D, Marasco A, Limongiello A, Marchetti C, Marie H, Tirozzi B, Migliore M (2012) On the mechanisms underlying the depolarization 
block in the spiking dynamics of CA1 pyramidal neurons. J Comput Neurosci 33:207-225. CrossRef Medline

Bittner KC, Milstein AD, Grienberger C, Romani S, Magee JC (2017) Behavioral time scale synaptic plasticity underlies CA1 place fields. Science 357:1033-1036. CrossRef Medline

Blatz AL, Magleby KL (1986) Single apamin-blocked ca-activated K+ channels of small conductance in cultured rat skeletal muscle. Nature 323: 718-720. CrossRef Medline

Bloodgood BL, Sabatini BL (2007) Nonlinear regulation of unitary synaptic signals by $\mathrm{CaV}(2.3)$ voltage-sensitive calcium channels located in dendritic spines. Neuron 53:249-260. CrossRef Medline

Bock T, Stuart G (2014) Impact of SK channels on cortical excitability in vivo. Program No. 304.08. 2014 Neuroscience Meeting Planner. Washington, DC: Society for Neuroscience.

Bond CT, Maylie J, Adelman JP (2005) SK channels in excitability, pacemaking and synaptic integration. Curr Opin Neurobiol 15:305-311. CrossRef Medline

Broicher T, Malerba P, Dorval AD, Borisyuk A, Fernandez FR, White JA (2012) Spike phase locking in CA1 pyramidal neurons depends on background conductance and firing rate. J Neurosci 32:14374-14388. CrossRef Medline

Buchanan KA, Petrovic MM, Chamberlain SE, Marrion NV, Mellor JR (2010) Facilitation of long-term potentiation by muscarinic M1 receptors is mediated by inhibition of SK channels. Neuron 68:948-963. CrossRef Medline

Cash S, Yuste R (1999) Linear summation of excitatory inputs by CA1 pyramidal neurons. Neuron 22:383-394. CrossRef Medline

Chatelain FC, Alagem N, Xu Q, Pancaroglu R, Reuveny E, Minor DL Jr (2005) The pore helix dipole has a minor role in inward rectifier channel function. Neuron 47:833-843. CrossRef Medline

Chen S, Benninger F, Yaari Y (2014) Role of small conductance $\mathrm{Ca}^{2+}$ activated $\mathrm{K}^{+}$channels in controlling CAl pyramidal cell excitability. J Neurosci 34:8219-8230. CrossRef Medline

Chen X, Yuan LL, Zhao C, Birnbaum SG, Frick A, Jung WE, Schwarz TL, Sweatt JD, Johnston D (2006) Deletion of Kv4.2 gene eliminates dendritic A-type $\mathrm{K}+$ current and enhances induction of long-term potentiation in hippocampal CA1 pyramidal neurons. J Neurosci 26:12143-12151. CrossRef Medline

Cohen J (1977) CHAPTER 1: The concepts of power analysis. In: Statistical power analysis for the behavioral sciences (revised edition). Available from: https://www.sciencedirect.com/science/article/pii/B9780121790608500062 [Accessed January 11, 2018].

Colgin LL, Moser EI (2010) Gamma oscillations in the hippocampus. Physiology 25:319-329. CrossRef Medline

Colgin LL, Denninger T, Fyhn M, Hafting T, Bonnevie T, Jensen O, Moser MB, Moser EI (2009) Frequency of gamma oscillations routes flow of information in the hippocampus. Nature 462:353-357. CrossRef Medline

Destexhe A, Mainen ZF, Sejnowski TJ (1995) Fast kinetic models for simulating AMPA, NMDA, GABA $A_{A}$ and $\mathrm{GABA}_{\mathrm{B}}$ receptors. In: The neurobiology of computation (JM Bower, ed), pp 9-14. Boston, MA: Springer.

Düzel E, Penny WD, Burgess N (2010) Brain oscillations and memory. Curr Opin Neurobiol 20:143-149. CrossRef Medline

Easton A, Fitchett AE, Eacott MJ, Baxter MG (2011) Medial septal cholinergic neurons are necessary for context-place memory but not episodiclike memory. Hippocampus 21:1021-1027. CrossRef Medline

Faber ES, Delaney AJ, Power JM, Sedlak PL, Crane JW, Sah P (2008) Modulation of SK channel trafficking by beta adrenoceptors enhances excitatory synaptic transmission and plasticity in the amygdala. J Neurosci 28:10803-10813. CrossRef Medline

Fernández-Ruiz A, Makarov VA, Benito N, Herreras O (2012) Schafferspecific local field potentials reflect discrete excitatory events at gamma frequency that may fire postsynaptic hippocampal CA1 units. J Neurosci 32:5165-5176. CrossRef Medline

Frick A, Magee J, Johnston D (2004) LTP is accompanied by an enhanced local excitability of pyramidal neuron dendrites. Nat Neurosci 7:126-135. CrossRef Medline

Gasparini S (2011) Distance- and activity-dependent modulation of spike back-propagation in layer $\mathrm{V}$ pyramidal neurons of the medial entorhinal cortex. J Neurophysiol 105:1372-1379. CrossRef Medline

Gasparini S, Magee JC (2006) State-dependent dendritic computation in hippocampal CA1 pyramidal neurons. J Neurosci 26:2088-2100. CrossRef Medline
Gasparini S, Migliore M (2015) Action potential backpropagation. In: Encyclopedia of computational neuroscience (Jaeger D, Jung R, eds), pp 133-137. New York, NY: Springer.

Gasparini S, Losonczy A, Chen X, Johnston D, Magee JC (2007) Associative pairing enhances action potential back-propagation in radial oblique branches of CA1 pyramidal neurons. J Physiol 580:787-800. CrossRef Medline

Giessel AJ, Sabatini BL (2010) M1 muscarinic receptors boost synaptic potentials and calcium influx in dendritic spines by inhibiting postsynaptic SK channels. Neuron 68:936-947. CrossRef Medline

Golding NL, Jung HY, Mickus T, Spruston N (1999) Dendritic calcium spike initiation and repolarization are controlled by distinct potassium channel subtypes in CA1 pyramidal neurons. J Neurosci 19:8789-8798. CrossRef Medline

Han P, Nakanishi ST, Tran MA, Whelan PJ (2007) Dopaminergic modulation of spinal neuronal excitability. J Neurosci 27:13192-13204. CrossRef Medline

Harvey CD, Collman F, Dombeck DA, Tank DW (2009) Intracellular dynamics of hippocampal place cells during virtual navigation. Nature 461: 941-946. CrossRef Medline

Hasselmo ME (2006) The role of acetylcholine in learning and memory. Curr Opin Neurobiol 16:710-715. CrossRef Medline

Hasselmo ME, Sarter M (2011) Modes and models of forebrain cholinergic neuromodulation of cognition. Neuropsychopharmacology 36:52-73. CrossRef Medline

Hasselmo ME, Schnell E (1994) Laminar selectivity of the cholinergic suppression of synaptic transmission in rat hippocampal region CA1: computational modeling and brain slice physiology. J Neurosci 14:38983914. CrossRef Medline

Higgs MH, Spain WJ (2009) Conditional bursting enhances resonant firing in neocortical layer 2-3 pyramidal neurons. J Neurosci 29:1285-1299. CrossRef Medline

Hoffman DA, Johnston D (1998) Downregulation of transient K+ channels in dendrites of hippocampal CA1 pyramidal neurons by activation of PKA and PKC. J Neurosci 18:3521-3528. CrossRef Medline

Hoffman DA, Johnston D (1999) Neuromodulation of dendritic action potentials. J Neurophysiol 81:408-411. CrossRef Medline

Hoffman DA, Magee JC, Colbert CM, Johnston D (1997) K+ channel regulation of signal propagation in dendrites of hippocampal pyramidal neurons. Nature 387:869-875. CrossRef Medline

Ishibashi M, Gumenchuk I, Miyazaki K, Inoue T, Ross WN, Leonard CS (2016) Hypocretin/Orexin peptides alter spike encoding by serotonergic dorsal raphe neurons through two distinct mechanisms that increase the late afterhyperpolarization. J Neurosci 36:10097-10115. CrossRef Medline

Jahr CE, Stevens CF (1990) Voltage dependence of NMDA-activated macroscopic conductances predicted by single-channel kinetics. J Neurosci 10:3178-3182. CrossRef Medline

Johnston D, Magee JC, Colbert CM, Cristie BR (1996) Active properties of neuronal dendrites. Annu Rev Neurosci 19:165-186. CrossRef Medline

Jones SL, Stuart GJ (2013) Different calcium sources control somatic versus dendritic SK channel activation during action potentials. J Neurosci 33: 19396-19405. CrossRef Medline

Jutras MJ, Buffalo EA (2010) Synchronous neural activity and memory formation. Curr Opin Neurobiol 20:150-155. CrossRef Medline

Kalmbach BE, Gray R, Johnston D, Cook EP (2017) Systems-based analysis of dendritic nonlinearities reveals temporal feature extraction in mouse L5 cortical neurons. J Neurophysiol 117:2188-2208. CrossRef Medline

Kemere C, Carr MF, Karlsson MP, Frank LM (2013) Rapid and continuous modulation of hippocampal network state during exploration of new places. PLoS One 8:e73114. CrossRef Medline

Kim J, Wei DS, Hoffman DA (2005) Kv4 potassium channel subunits control action potential repolarization and frequency-dependent broadening in rat hippocampal CA1 pyramidal neurones. J Physiol 569:41-57. CrossRef Medline

Knauer B, Jochems A, Valero-Aracama MJ, Yoshida M (2013) Long-lasting intrinsic persistent firing in rat CA1 pyramidal cells: a possible mechanism for active maintenance of memory. Hippocampus 23:820-831. CrossRef Medline

Lin EC, Combe CL, Gasparini S (2017) Differential contribution of $\mathrm{Ca}^{2+}$. dependent mechanisms to hyperexcitability in layer $\mathrm{V}$ neurons of the medial entorhinal cortex. Front Cell Neurosci 11:182. CrossRef Medline 
Magee JC (1998) Dendritic hyperpolarization-activated currents modify the integrative properties of hippocampal CA1 pyramidal neurons. J Neurosci 18:7613-7624. CrossRef Medline

Magee JC (2016) Dendritic voltage-gated ion channels. In: Dendrites, Ed 2 (Stuart GJ, Spruston N, Hausser M, eds), pp 259-284. Oxford: OUP.

Maingret F, Coste B, Hao J, Giamarchi A, Allen D, Crest M, Litchfield DW, Adelman JP, Delmas P (2008) Neurotransmitter modulation of smallconductance $\mathrm{Ca}^{2+}$-activated $\mathrm{K}^{+}$channels by regulation of $\mathrm{Ca}^{2+}$ gating. Neuron 59:439-449. CrossRef Medline

Marder E (2012) Neuromodulation of neuronal circuits: back to the future. Neuron 76:1-11. CrossRef Medline

Markram H, Segal M (1990) Acetylcholine potentiates responses to $\mathrm{N}$-methyl-D-aspartate in the rat hippocampus. Neurosci Lett 113:62-65. CrossRef Medline

McDermott CM, Hardy MN, Bazan NG, Magee JC (2006) Sleep deprivation-induced alterations in excitatory synaptic transmission in the CA1 region of the rat hippocampus. J Physiol 570:553-565. CrossRef Medline

Megías M, Emri Z, Freund TF, Gulyás AI (2001) Total number and distribution of inhibitory and excitatory synapses on hippocampal CA1 pyramidal cells. Neuroscience 102:527-540. CrossRef Medline

Ngo-Anh TJ, Bloodgood BL, Lin M, Sabatini BL, Maylie J, Adelman JP (2005) SK channels and NMDA receptors form a $\mathrm{Ca}^{2+}$-mediated feedback loop in dendritic spines. Nat Neurosci 8:642-649. CrossRef Medline

Obermair GJ, Kaufmann WA, Knaus HG, Flucher BE (2003) The small conductance $\mathrm{Ca}^{2+}$-activated $\mathrm{K}^{+}$channel SK3 is localized in nerve terminals of excitatory synapses of cultured mouse hippocampal neurons. Eur J Neurosci 17:721-731. CrossRef Medline

Pedarzani P, McCutcheon JE, Rogge G, Jensen BS, Christophersen P, Hougaard C, Strøbaek D, Stocker M (2005) Specific enhancement of SK channel activity selectively potentiates the afterhyperpolarizing current I(AHP) and modulates the firing properties of hippocampal pyramidal neurons. J Biol Chem 280:41404-41411. CrossRef Medline

Perrier JF, Rasmussen HB, Christensen RK, Petersen AV (2013) Modulation of the Intrinsic Properties of Motoneurons by Serotonin. Curr Pharm Des 19:4371-4384. Medline

Pewsey A (2004) The large-sample joint distribution of key circular statistics. Metrika 60:25-32.

Pewsey A, Neuhäuser M, Ruxton GD (2013) Circular statistics in R. Oxford: OUP.

Poirazi P, Brannon T, Mel BW (2003) Pyramidal neuron as two-layer neural network. Neuron 37:989-999. CrossRef Medline

Prado VF, Janickova H, Al-Onaizi MA, Prado MA (2017) Cholinergic cir- cuits in cognitive flexibility. Neuroscience 345:130-141. CrossRef Medline

Schomburg EW, Fernández-Ruiz A, Mizuseki K, Berényi A, Anastassiou CA, Koch C, Buzsáki G (2014) Theta phase segregation of input-specific gamma patterns in entorhinal-hippocampal networks. Neuron 84:470 485. CrossRef Medline

Schram G, Pourrier M, Wang Z, White M, Nattel S (2003) Barium block of Kir2 and human cardiac inward rectifier currents: evidence for subunitheteromeric contribution to native currents. Cardiovasc Res 59:328-338. CrossRef Medline

Shah MM, Migliore M, Valencia I, Cooper EC, Brown DA (2008) Functional significance of axonal Kv7 channels in hippocampal pyramidal neurons. Proc Natl Acad Sci U S A 105:7869-7874. CrossRef Medline

Stocker M, Krause M, Pedarzani P (1999) An apamin-sensitive $\mathrm{Ca}^{2+}$. activated $\mathrm{K}+$ current in hippocampal pyramidal neurons. Proc Natl Acad Sci U S A 96:4662-4667. CrossRef Medline

Teles-Grilo Ruivo LM, Baker KL, Conway MW, Kinsley PJ, Gilmour G, Phillips KG, Isaac JTR, Lowry JP, Mellor JR (2017) Coordinated acetylcholine release in prefrontal cortex and hippocampus is associated with arousal and reward on distinct timescales. Cell Rep 18:905-917. CrossRef Medline

Wang K, Lin MT, Adelman JP, Maylie J (2014) Distinct $\mathrm{Ca}^{2+}$ sources in dendritic spines of hippocampal CA1 neurons couple to SK and Kv4 channels. Neuron 81:379-387. CrossRef Medline

Watson GS, Williams EJ (1956) On the construction of significance tests on the circle and the sphere. Biometrika 43:344-352.

Winters BD, Bussey TJ (2005) Removal of cholinergic input to perirhinal cortex disrupts object recognition but not spatial working memory in the rat. Eur J Neurosci 21:2263-2270. CrossRef Medline

Yamada-Hanff J, Bean BP (2013) Persistent sodium current drives conditional pacemaking in CA1 pyramidal neurons under muscarinic stimulation. J Neurosci 33:15011-15021. Medline

Zemankovics R, Veres JM, Oren I, Hájos N (2013) Feedforward inhibition underlies the propagation of cholinergically induced gamma oscillations from hippocampal CA3 to CA1. J Neurosci 33:12337-12351. CrossRef Medline

Zheng C, Bieri KW, Hwaun E, Colgin LL (2016a) Fast gamma rhythms in the hippocampus promote encoding of novel object-place pairings. eNeuro 3:ENEURO.0001-16.2016. CrossRef Medline

Zheng C, Bieri KW, Hsiao YT, Colgin LL (2016b) Spatial sequence coding differs during slow and fast gamma rhythms in the hippocampus. Neuron 89:398-408. CrossRef Medline 